IZA DP No. 9774

Circadian Rhythms, Sleep and Cognitive Skills:

Evidence from an Unsleeping Giant

Osea Giuntella

Wei Han

Fabrizio Mazzonna

February 2016 


\title{
Circadian Rhythms, Sleep and Cognitive Skills: Evidence from an Unsleeping Giant
}

\author{
Osea Giuntella \\ University of Oxford \\ and IZA
}

Wei Han

University of Oxford

Fabrizio Mazzonna

University of Lugano

\section{Discussion Paper No. 9774 \\ February 2016}

\author{
IZA \\ P.O. Box 7240 \\ 53072 Bonn \\ Germany
}

Phone: +49-228-3894-0

Fax: +49-228-3894-180

E-mail: iza@iza.org

Any opinions expressed here are those of the author(s) and not those of IZA. Research published in this series may include views on policy, but the institute itself takes no institutional policy positions. The IZA research network is committed to the IZA Guiding Principles of Research Integrity.

The Institute for the Study of Labor (IZA) in Bonn is a local and virtual international research center and a place of communication between science, politics and business. IZA is an independent nonprofit organization supported by Deutsche Post Foundation. The center is associated with the University of Bonn and offers a stimulating research environment through its international network, workshops and conferences, data service, project support, research visits and doctoral program. IZA engages in (i) original and internationally competitive research in all fields of labor economics, (ii) development of policy concepts, and (iii) dissemination of research results and concepts to the interested public.

IZA Discussion Papers often represent preliminary work and are circulated to encourage discussion. Citation of such a paper should account for its provisional character. A revised version may be available directly from the author. 
IZA Discussion Paper No. 9774

February 2016

\section{ABSTRACT \\ Circadian Rhythms, Sleep and Cognitive Skills: Evidence from an Unsleeping Giant ${ }^{*}$}

This paper analyzes the effects of sleep duration on cognitive skills and depression symptoms of older workers in China. Cognitive skills and mental health have been associated with sleep duration and are known to be strongly related to economic behavior and performance. However, causal evidence is lacking and little is known about sleep deprivation in developing countries. We exploit the relationship between circadian rhythms and bedtime to identify the effects of sleep using sunset time as an instrument. Using the Chinese Health and Retirement Longitudinal Study, we show that a later sunset time reduces significantly sleep duration and that sleep duration increases cognitive skills and eases depression symptoms of workers aged over 45 years. The results are driven by employed individuals living in urban areas, who are more likely to be constrained by rigid working schedules. On the contrary, we find no evidence of significant effects on self-employed and farmers.

JEL Classification: $\quad$ I12

Keywords: $\quad$ sleep deprivation, cognitive skills, risky behaviors

Corresponding author:

Osea Giuntella

University of Oxford

Nuffield College

Blavatnik School of Government

1 New Road

OX11NF, Oxford, Oxfordshire

United Kingdom

E-mail: osea.giuntella@nuffield.ox.ac.uk

\footnotetext{
* We are thankful to Daniele Paserman, Guglielmo Weber for their comments and suggestions. We also thank seminar attendees at the University of Oxford and at the Conference on Health, Demography and Aging in China, Stanford Center for International Development, October 2015.
} 


\section{Introduction}

Growing evidence on a downward trend in average sleep duration, along with an increased incidence of sleep deprivation has raised concern about the potential effects on population health and health care costs (Roenneberg, 2013). Insufficient sleep is associated with a reduction in daytime alertness; excessive daytime sleepiness, which impairs memory and cognitive ability (Alhola and Polo-Kantola, 2007; Killgore, 2010); occupational and automobile injuries (Dinges, 1995); poor health and obesity (see Cappuccio et al., 2010, for a systematic review). Though most sleep research has focused on developed countries, recent studies suggest that sleep disturbances in the developing world are far higher than previously thought (Stranges et al., 2012). This paper analyzes the effects of sleep duration on the cognitive skills and depression symptoms of older workers (45 and above) in China.

According to the estimates of the China Sleep Research Society, approximately $40 \%$ of Chinese suffer from a sleeping disorder. ${ }^{1}$ Luo et al. (2013) also suggest that approximately two out of five elderly people living in urban China have sleep problems and that this rate increases rapidly with ageing. The rapid growth of the Chinese economy and the "electronification" of the bedroom have contributed to the observed increase in the number of people reporting insufficient sleep (e.g., Li et al., 2007). Besides, sleeping is often considered as an unproductive use of time, a cost that should be minimized especially in a period of rapid economic expansion, despite the common wisdom that sleeping a sufficient number of hours is important for health and performance (Pan, 2004). In addition, sleep is often regarded as a manifestation of laziness in the Chinese traditional culture, in which working hard and diligently is highly praised, so that people tend to belittle their sleep problems (Xiang et al., 2008; Pan, 2004). Paradoxically, the pressures of a rapidly growing economy may have unintended consequences on sleep quality and duration, and in turn individual performance.

Cognitive skills have been shown to be strongly related to economic outcomes (McArdle et al., 2011), financial decisions such as portfolio choices (Banks and Oldfield, 2007), and economic development (Hanushek and Woessmann, 2008). As argued by Lei et al. (2012), the degradation of cognitive skills associated with ageing may have important effects in countries such as China with an ageing population and lacking intermediary institutions providing support to older people making decisions on income security or health care provision. Medical and psychiatric studies provide also evidence of an important association between sleep deprivation and depression (Tsuno et al., 2005; Wirz-Justice and Van den Hoofdakker, 1999). For long-time researchers thought China was characterized by a relatively low prevalence of depression, yet studies analyzing more recent data find high rates of depression among Chinese older adults (Lei et al., 2014).

There is a quite voluminous medical literature studying the associations between sleep deprivation, cognitive abilities, and mental health in laboratory settings. However, the experimental

\footnotetext{
${ }^{1}$ See also http://www . asrsonline org. Accessed on February 20, 2016.
} 
evidence focused mainly on the effects of total sleep deprivation (being awake continuously for one to three days, or sleeping less than fours hours for few days in a row). Only few studies evaluate the consequences of chronic partial sleep deprivation (i.e. repeated exposure to sleep duration of less than six to seven hours per night), a condition that is far more common in reality but received less attention because of the limited ability to collect sleep data or observe subjects over time (see Section 2 for a review). Furthermore, as recently remarked by Roenneberg (2013), laboratory studies offer a very limited understanding of both the determinants and consequences of sleep deprivation as they are usually based on people who have been instructed to follow certain sleep patterns (e.g., bedtime), and laboratory settings are unlikely to reflect realworld conditions (e.g., individuals are often required to sleep with electrodes fastened to their heads). On the other hand, observational studies have mostly relied on descriptive analysis of survey data which does not allow to disentangle the causal effect of sleeping from that of other unobservable confounding factors. Despite a growing interest on the topic, we still know very little about the causal effects of sleep on health, human capital and productivity. Hence, evidence is lacking on the mechanisms that may underlie the relationship between sleep duration and economic performance.

Our contribution with respect to the extant literature is two-fold. First, to the best of our knowledge there are no other studies using a quasi-natural experiment and survey data to identify the effects of sleep duration on cognitive skills. Second, there is very little evidence on the relationship between sleep duration and cognitive skills in developing countries.

Our study also contributes to a small but growing strand of the economic literature analyzing the determinants and consequences of sleeping. Though people spend a large part of their time sleeping and despite a large variation in sleeping patterns in the population, the determinants of sleeping choices and their consequences have been largely understudied in the economic literature. Most economic models, indeed, consider sleeping as a predetermined constraint on individual's time use or more generally as standard leisure time that can be traded-off when relative returns to market activities or to other leisure activities increase. A few notable exceptions have analyzed how sleeping duration responds to market incentives (Biddle and Hamermesh, 1990). Empirical studies have examined the effect of daylight saving time on car crashes, work accidents, health, and financial markets (Barnes and Wagner, 2009; Sood and Ghosh, 2007; Monk, 2012; Kamstra et al., 2000; Jin and Ziebarth, 2015; Smith, forthcoming) as well as differences in productivity between different chronotypes, morning vs. evening types (Bonke, 2012). In particular, our paper is closely related to two recent studies analyzing the effects of sleep deprivation on productivity (Gibson and Shrader, 2014) and health (Giuntella and Mazzonna, 2015).

This paper is also related to the growing number of studies on the effects of school start times on academic achievement (Carrell et al., 2011; Edwards, 2012; Stewart, 2014). These studies show that even differences of 20 or 30 minutes delay of school start times can have important effects on academic outcomes (Carrell et al., 2011; Owens et al., 2010). However, this literature focuses only on children and young adults and does not improve our understanding about the medium 
and "long-term" effects of chronic restrictions to sleep duration. In addition, our study speaks to the previous literature analyzing the determinants of cognitive skills and mental health (Banks and Dinges, 2011; Banks and Oldfield, 2007; Mazzonna and Peracchi, 2012), and in particular to those studies focusing on older workers and on ageing and cognitive skills in China (Lei et al., 2012; Huang and Zhou, 2013; Lei et al., 2014).

To identify the effects of sleep duration on cognitive skills we adopt an instrumental variable strategy and follow the same approach used by Gibson and Shrader (2014) who examine the effects of sleep on productivity in the US by exploiting variation in sunset time and its effects on bedtime within US time zones. Our instrumental variable strategy exploits the same relationship between circadian rhythms and bedtime in the particular context of China, a country roughly as broad as continental US but following a single time zone. Due to circadian rhythms, our body reacts to environmental light producing more melatonin when darker. Thus, when sunset occurs at a later hour, individuals tend to go to bed at later time (Roenneberg and Merrow, 2007). While individuals, in principle, could compensate for a later bedtime by waking up later in the morning, social schedules (e.g., working schedules, school start times) are less responsive to solar cues and tend to respond to economic incentives and returns to coordination (Hamermesh et al., 2008). For these reasons, a later sunset can have important effects on sleep duration.

Because of the single standard time zone, there are large differences in both sunrise and sunset time between cities, far larger than those exploited by Gibson and Shrader (2014) in the US. For instance, on June 21, in the city of Urumqui, in north-west China, the sun rises at 6.27am and sets at $9.56 \mathrm{pm}$, with the solar noon occurring at $2.11 \mathrm{pm}$, while in Harbin in north-east China, the sun rises at $3.43 \mathrm{am}$ and sets at $7.27 \mathrm{pm}$, with the solar noon occurring at 11.35am (see Figure $1)$.

Our identification strategy exploits this variation in sunset time to identify the effects of sleep duration on cognitive outcomes. Using data from the Chinese Health and Retirement Longitudinal Study (CHARLS), we focus on the effects of sleeping on cognitive skills of a relatively old population (45 and above). We show that individuals living in cities where the sun sets at a later time, ceteris paribus, sleep less than individuals living in early sunset cities. Using sunset time as an instrument for sleep duration, we show that increasing sleeping time by an hour increases significantly the scores reported in cognitive tests measuring mental and numerical skills. A one-hour change in sleep duration produces effects on cognitive outcomes ranging from 0.4 to 0.6 standard deviations. These effects are consistent with the growing evidence from neurobiological studies that even relatively moderate sleep restriction can severely affect waking neurobehavioral functions and that repeated exposure to partial sleep deprivation ("sleep debt") may increase the severity of age-related chronic disorders (Van Dongen et al., 2003; Spiegel et al., 1999). The effects are driven by the employed population living in urban areas. These results are consistent with the idea that in rural areas schedules tend to adjust to the daily solar cycle, while in urban contexts employed individuals are constrained in the morning by working schedules and cannot fully compensate for a later bedtime. Results, using dummies for particular sleep 
ranges as dependent variables, are qualitatively similar.

A natural concern is that the geographical distribution of economic activity may confound our effect of interest. To partially address this issue we use only within-region variation and control extensively for local economic conditions. Furthermore, it is reassuring that the relationship between sunset time and sleeping time is driven by individuals whose time use is constrained by working schedules. In particular we find that the results are statistically significant and economically important among the employed living in urban areas, while they are smaller and non-significant among non-employed, self-employed and farmers whose schedules are more flexible or more likely to respond to the solar cycle. Finally, we find non-significant effects on health outcomes that are usually correlated with economic activity but should not be affected by sleeping (or sunset) time such as individual's knee height -measured using a Martin caliper from the right knee joint to the ground- and individual's health as a child (Huang et al., 2013).

Overall, our results suggest that sleeping has important effects on cognitive performance and depression symptoms. The heterogeneity of our results by occupational and demographic characteristics is consistent with recent findings from other countries (Giuntella and Mazzonna, 2015) and suggests that sleeping duration is importantly affected by social constructs such as working schedules that create a misalignment between social and biological time (Wittmann et al., 2006). Our findings also suggest that while coordination has clear economic advantages (Hamermesh et al., 2008), its costs should not be neglected.

The paper is organized as following. In Section 2 we provide a review of the literature analyzing sleep deprivation and cognitive skills. Section 3 illustrates our identification strategy and the data used in our analysis. Section 4 discusses the results. Conclusions are in Section 5.

\section{Sleep Deprivation and Cognitive Skills}

The effects of sleep deprivation have been extensively studied in laboratory settings. The majority of experiments focuses on acute total sleep deprivation, in which participants are kept awake continuously, generally for one to three days, and their cognitive performance is tested before, during and after experiments. Alhola and Polo-Kantola (2007) and Killgore (2010) reviewed the effects of acute total sleep deprivation on a wide range of cognitive processes, including basic cognitive functions such as attention, multiple aspects of sensory perception, emotional processing, learning, memory, and decision making. Despite the different methodologies, most studies suggest that sleep deprivation induces cognitive impairment, and that individual characteristics affect the tolerance of sleep deprivation.

Chronic partial sleep deprivation is more common in reality due to several factors, including sleep disorders, work demands, and social and domestic duties; however, it received much less attention due to the difficulty of analyzing individual sleep duration over a long enough period. Earlier studies yielded mixed findings as a result of defectively designed experiments, but recent studies, with improved experimental control groups, consistently find that chronic sleep depri- 
vation adversely affected cognitive performance, in particular behavioral alertness (Banks and Dinges, 2011). For instance, the most extensive, controlled dose-response experiment on chronic sleep restriction was based on 14 days of sleep limitation to no more than four, six, or eight hours (Van Dongen et al., 2003). Those with four or six hours of sleep report negative effects comparable to those individuals forced to stay awake for 24 or 48 hours. Moreover, the experiment shows evidence of cumulative dose-response effects on neurobehavioral functions. In other words, additional days of sleep restriction resulted in additional neurobehavioral impairments. Unfortunately, the external validity of these experimental studies is rather limited. In the real world, people are often exposed to partial sleep deprivation for long time (months, years), a condition that cannot be reproduced and examined in a laboratory setting.

On the other hand, there are several observational studies analyzing the relationship between sleep duration and cognitive skills. However, survey-based study can hardly establish any causal relationship (see Yaffe et al., 2014, for a comprehensive review). Overall, these existent surveybased studies yield mixed results (Benito-León et al., 2009; Hahn et al., 2014).

In the economic literature, a few studies have attempted to recover the causal effect of school start times on academic performance. Carrell et al. (2011) identify the causal effect of school start times on academic achievement by using two policy changes in the daily schedule at the US Air Force Academy along with the randomized placement of freshman students to courses and instructors. They find that starting the school day 30 minutes later has a significant and economically important positive effect on student achievement. However, they cannot observe sleep. Furthermore, this study does not provide any evidence regarding the effect of chronic sleep deprivation and does not consider the cumulative and long-run effects of partial sleep deprivation.

An important contribution of our paper is the focus on a developing economy. Most of the studies analyzing the effect of sleep deprivation focus on individuals living in advanced economies. In particular, because of the ongoing ageing of the population, there is increased attention on the sleep deprivation and sleep quality of older adults in low- and middle-income countries. Indeed, the evidence from the medical literature suggests a greater occurrence of sleep disorders among older adults due to deterioration of the suprachiasmatic nucleus region of the brain (Van Someren, 2000). The deterioration of sleep quality among the elderly may contribute to cognitive decline. Furthermore, as family members (spouses and adult children) are the predominant caregivers in China (United Nations) the degradation of cognitive skills of the elderly may impose an additional burden on prime-age workers. ${ }^{2}$

Yet, there is very little evidence on the causal effects of sleep deprivation on cognitive skills, and sleep deprivation has been largely understudied in developing countries. Gildner et al. (2014) and Stranges et al. (2012) are two notable exceptions, analyzing the association between sleep deprivation and cognitive outcomes in low- and middle-income countries. In a recent

\footnotetext{
${ }^{2}$ http:/ / www.unescap.org/sites/default/files/Long\%20Term\%20Care\%20for\%20older\%20persons\%20in\%20China.pdf. Accessed on February 20, 2016.
} 
study, Luo et al. (2013) analyzing 1086 community residents aged 60 years who completed the Chinese version of the Pittsburgh Sleep Quality Index (CPSQI) find that poor sleep quality is highly prevalent among elderly Chinese residents in urban Shanghai. However, as most other studies on the topic, they do not attempt to recover the causal effect of sleep deprivation.

\section{Identification Strategy and Empirical Specification}

\subsection{Background: Time Zones in China}

China is the second largest country in the world by land area and the most populous. Its territory spans over 60 degrees of longitude. As described in Figure 2, under a standard scheme Chinese territory would cover an area corresponding to five time zones ranging from UTC +5 to UTC+9. In 1912, the year after the collapse of the Qing Dynasty, the newly empowered Republic of China established five different time zones in the country, ranging from five and a half to eight and a half hours past Greenwich Mean Time. But in 1949 Mao Zedong decreed that all of China would henceforth be on Beijing time. As the Communist Party consolidated control of the country, the one time zone was meant to foster national unity (Gilley, 2004). ${ }^{3}$ For the past 60 years, all of China has shared a single official time zone. Since 1949, the official national standard time is eight hours ahead of Greenwich Mean Time (UTC+8), referred to as Beijing Time domestically and as China Standard Time internationally. This common national time produces some geographic distortions. When at sunrise in Beijing a daily flag raising ceremony takes place in Tiananmen Square, easternmost China has already experienced an hour of daylight, but in the westernmost part of China the sun will not rise for another three hours.

Mainland China is administered in 31 provincial level administrative divisions (22 provinces, five autonomous regions and four provincial level municipalities). Figure 2 shows that most provinces are located in UTC +7 and UTC +8 where $95 \%$ of the Chinese population lives. Thus, for most people in China the single time zone simply requires a little or moderate adjustment. The provincial level administrative divisions located within UTC+8 longitudes include Fujian, Jiangxi, Zhejiang, Anhui, Shanghai, Jiangsu, Shandong, Hebei, Beijing, Tianjin, Liaoning, at least half of the areas of Hubei, Henan, Shanxi, Guangdong, Jilin, Inner Mongolia, Heilongjiang, and about one-third of Hunan. As reported in Table 1, with an estimated population of 0.77 billion people $(56 \%)$, the UTC +8 produced $65 \%$ of China's GDP in $2014 .{ }^{4}$ Almost all the remaining population and economic activity is located in the UTC +7 .

A number of minority Muslim Uighur citizens of Xinjiang Uyghur Autonomous Region province do not observe official "Beijing time". Indeed, Xinjiang, located in the westernmost part of the country, operates on a two-time zone system: the official "Beijing Time" and the

\footnotetext{
${ }^{3}$ India had established a similar policy in 1947, after independence.

${ }^{4}$ Author's own calculation based on China Statistical Yearbook (2014). For the provinces having at least half of the areas located within UTC +8 longitudes, we count $50 \%$ of their population and GDP; for Hunan, we count $30 \%$ of its population and GDP.
} 
unofficial "Xinjiang Time" (UTC+6). While schools, government offices, public service offices, airports and railway stations all adopt Beijing time; some bus lines and local shops use local Xinjiang Time. For those following Beijing Time, they implement a modified time schedule. For instance, schools start at 10am Beijing Time, which equals to 8 am Xinjiang Time. For this reason, we excluded Xinjiang and all individuals living in UTC +5 and UTC +6 from our sample focusing on individuals living in UTC +7 , UTC +8 , and UTC +9 . In these three areas, work schedules and economic activity are coordinated. Offices, shops, public transportation and schools follow the Beijing time.

\subsection{Identification Strategy}

The goal of this paper is to recover the causal effects of sleep duration on cognition and depression. A simple comparison of people with different sleeping behavior would not allow us to identify a causal relationship. A natural concern is that there may be omitted variables that are both related to sleep duration and our outcomes of interest. Moreover, depression and cognitive impairment can affect sleep duration, generating a reverse causality problem. For these reasons, we rely on an instrumental variable (IV) strategy to identify the effects of sleep on cognitive skills and depression symptoms using information on sunset time. More specifically, our identification strategy exploits the geographical variation in sunset time across Chinese cities as sources of exogenous variation in sleep duration.

Our strategy is the same as the one used by Gibson and Shrader (2014) to analyze the effects of sleep duration on productivity in the US and it is closely related to the approach used by Giuntella and Mazzonna (2015) who use discontinuities in sunset at a time zone border to recover the causal effects of sleep deprivation on health. The main idea underlying these strategies is that circadian rhythms are important determinants of human sleeping patterns. Our internal pacemaker, the brain's suprachiasmatic nucleus (SCN), also known as the body's master clock, regulates the body's biological rhythms by changing the concentrations of the molecular components of the clock to levels consistent with the appropriate stage in the 24-hour cycle. This process is known as "entrainment". In practice, when the sun sets and it becomes darker, the SCN produces more melatonin facilitating sleep (Aschoff et al., 1971; Duffy and Wright, 2005; Roenneberg et al., 2007; Roenneberg and Merrow, 2007). Within a time zone people organize their lives according to common social time, yet differences in sunrise and sunset time can be very large as dawn and dusk progress from east to west (Roenneberg and Merrow, 2007; Gibson and Shrader, 2014). Previous studies show that wake-up time is less affected by solar cues than bedtime. Instead, wake-up times are importantly affected by work schedules and other social constraints (such as children's school start times) which, in turn, respond to social conventions, economic incentives, and regional coordination (Hamermesh et al., 2008; Giuntella and Mazzonna, 2015; Roenneberg, 2013). Thus sunset time can have important effects on sleep duration.

Figure 1 illustrates the variation in sunset time across Chinese cities on Summer Solstice, June 21st. Because China follows a unique time zone the differences between the easternmost 
and the westernmost regions of China are marked. ${ }^{5}$ If people would compensate by waking up later this would have no effect on sleep duration. However, because of economic incentives and coordination, many individuals are not able to fully compensate in the morning by waking up at a later time. In particular, we expect sunset time to have larger effects on sleep duration among employed people in urban areas, as they are more likely to be constrained by standardized office hours. On the other hand, we expect that the sleeping behavior of people who are not employed or live in rural areas would be less affected by these differences in sunset time because their daily activities are more likely to respond to the daily solar cycle. In Section 4, we provide evidence consistent with this hypothesis.

The economic activity in China is clustered on the eastern side of the country. Thus, one may confound the positive effect of an early sunset on the eastern side of the country with the economic development of these areas. For this reason, we control for regional fixed effects in all our specifications. We consider four regions in accordance with the definition used in the Twelfth Five-Year Plan for National Economic and Social Development of China (see Figure 3). ${ }^{6}$ The eastern region, the most developed area, consists of 10 provincial level administrative divisions, eight of which are entirely within $\mathrm{UTC}+8$. The north-eastern region covers three provinces located either in UTC +8 or UTC +9 . The central region includes four provinces stretching over $\mathrm{UTC}+7$ and $\mathrm{UTC}+8$ as well as two provinces located in UTC +8 only. The remaining 12 provincial level administrative divisions constitute the western region, a vast territory characterized by lower socio-economic status and higher poverty rates. The western region ranges from UTC +5 to UTC +7 but only Xinjiang, Tibet, part of Gansu and Qinghai provinces are located in UTC +5 and UTC +6 , all of which have a low population density. ${ }^{7}$ Therefore, focusing only on individuals living in UTC $+7, \mathrm{UTC}+8$, and UTC +9 only excludes a tiny fraction of the population. In addition, we include controls for urban/rural status, GDP, population, type of landscape and level of air pollution at the city level. In practice, we exploit cross-sectional variation in average sunset time within regions that are considered to be homogeneous with respect to socio-economic characteristics. Table A.1 illustrates the within-region variation in sunset time for our baseline sample. In Section 4.1, we show that not adequately controlling for socio-economic differences leads to a downward bias (in absolute value), as individuals in richer areas tend to sleep less, but a higher socio-economic status is positively associated with cognitive and health outcomes (Cutler et al., 2011).

We acknowledge that there may be other unobserved confounding factors that may be correlated with average sunset time and our main outcomes of interest. Yet, we think that this concern is substantially mitigated by the inclusion of regional fixed effects and economic controls at the city level.

\footnotetext{
${ }^{5}$ It is worth reminding that sunset differences are not only determined by the longitude of a location but also by the latitude, with northern cities having longer days in the summer and shorter days in the winter with respect to cities in the south of the country.

${ }^{6}$ See http://www.gov.cn/2011lh/content_1825838.htm. Accessed on February 20, 2016.

${ }^{7}$ For a list of provinces by region, please see China Statistical Yearbook for Regional Economy (2012).
} 
Our identification relies on the assumption that conditional on our set of controls at the individual and regional level, sunset time is orthogonal to other characteristics that can affect our outcomes of interest. As any identification assumption, it is directly untestable. However, we show that individuals living in early and late sunset cities are well-balanced on most covariates and we implement some robustness checks on predetermined characteristics, such as child health and individual's knee height, that should not be affected by our instrument, but that are likely to be correlated with the level of economic development of the city. Furthermore, the heterogeneity of our findings by employment status and urban area appears to be consistent with our identification assumption. As previously noted, we expect and show that the largest effect of sunset time on sleeping behavior is observed among employed individuals living in urban areas. Instead, we find no evidence of significant effects of sunset on population that are more flexible with their individual schedules (self-employed) or more likely to adapt to the daily solar cycle (individuals in rural areas). For these groups there is also no evidence of significant reduced form effects on cognitive abilities. For this reason, our main sample consists of people still employed and living in urban areas.

It is worth noting that the cognitive differences that arise from contrasting cities with different sunset times are likely to be the result of a long-term exposure to sleep deprivation and are not the result of the effect of differences in sleeping behavior in the last month as measured in the data used in this paper (see Section 3.4). In other words, what we measure with our two-stage least squares (2SLS) strategy is not the effect of one-hour difference in average sleeping in the previous month, but rather the average effect of a "long-term" exposure to one-hour difference in sleeping. Moreover, if the negative effects of a long exposure to sleep deprivation are long lasting, we should find the presence of a reduced-form effect of the average sunset time on cognitive abilities also among subgroups that are no longer "treated"-people whose sleeping behavior is no longer affected by average sunset time. Specifically, we can find a reduced-form effect also on retired individuals that used to be treated but that can now compensate by waking up later in the morning, because social constraints (e.g. working schedules) are no longer binding. This suggests that we should interpret our 2SLS results with caution taking into account the fact that they can reflect both short and "long-term" effects.

Another concern that might arise is that our identification strategy could also reflect differences in sunlight exposure and, thus, violate the exclusion restriction assumption. In other words, if the differences in sunset time are correlated with the sunlight exposure we might confound the effect of sleep duration with that of the sunlight. For instance, sunlight exposure increases the production of vitamin D, which is usually associated with mood and depression (e.g., Kjærgaard et al., 2012). If we consider that the average sleep duration in our sample is 6.3 hours it is very likely that, regardless of their location, most of the Chinese people are usually awake (and then potentially exposed to sunlight) during all sunshine hours. Nevertheless, in our study, if there is a difference in sunlight exposure across Chinese cities, this should advantage individuals living in late sunset cities. Yet, we show that these individuals tend to sleep less. This means that, 
if ever, the difference in daily exposure to sunset light may introduce a downward bias in the estimated effect of sunset time on sleep duration and cognitive abilities.

Residential sorting and commuting may be other important confounding factors. The household registration system (Hukou) implemented in China since 1949 mitigates substantially the concern of residential sorting. Under this system, every citizen must register Hukou location and type (i.e. a single permanent place of residence and whether it is classified as urban or rural residence, respectively), which are passed on by one's parent(s) at birth regardless where the one physically resides in (Chan and Zhang, 1999). The access to most of public services and welfare benefits, such as children's education, housing, social security programs, are attached to one's Hukou. Indeed, in our data less than $1 \%$ of the respondents live in a city that is different from that of their Hukou, and more generally less than 3\% live in a province that is different from that of their birthplace. Finally, one may be concerned that if commuting tends to go in a certain direction (e.g. west to east), then commuting times may be correlated with sunsets as well as with sleep duration. Unfortunately, the CHARLS data do not contain information on individual commuting time. However, in 2015, Baidu, the country's largest Internet search company, used smartphones' data to estimate average commuting time and distance in China. According to the Baidu's analysis, the national average commuting distance in 2015 was $9.18 \mathrm{~km}$ with an average travelling time of 28 minutes. The individuals commuting the longest were traveling between Tongzhou to Beijing, approximately $50 \mathrm{~km}$. While commuting may importantly affect sleeping time, these distances are unlikely to reflect in significant differences in sunset time and thus unlikely to be correlated with our instrument. ${ }^{8}$

\subsection{Empirical Specification}

Formally, we estimate the following equation:

$$
C_{i c t}=\beta_{0}+\beta_{1} S_{i c t}+\beta_{2} X_{i c t}+\beta_{3} K_{c t}+\beta_{4} I_{i c t}+\eta_{r}+\epsilon_{i c t}
$$

where $C_{i c t}$ is a metric for cognitive skills or depression measure for individual $i$, living in city $c$ and interviewed on date $t ; S_{i c t}$ is the self-reported average sleep duration in the last month for individual $i$ in city $c$ on date $t ; X_{i c t}$ are standard socio-demographic controls at the individual level (age, gender, education, marital status, subjective income, household consumption, Hukou status and birthplace); $K_{c t}$ are a set of economic and geographic characteristics of the city $c$ (GDP, population, pollution level, landscape); $I_{i c t}$ are the interview characteristics (survey wave and month fixed effects); and $\eta_{r}$ are regional fixed effects.

As already mentioned, ordinary least squares do not allow the recovery of unbiased estimates of the effect of sleeping on cognition $\left(\beta_{1}\right)$ because of both reverse causality and unobservable individual characteristics that are not included in our large set of controls (e.g., stress or latent

\footnotetext{
${ }^{8}$ http://www.scmp.com/news/china/article/1692839/beijingers-lead-chinas-pack-longest-daily-commute. Accessed on February 20, 2016.
} 
health). For this reason we use an IV strategy that exploits differences in sunset time across Chinese cities as sources of exogenous variation in sleep duration. More specifically, we estimate the following first-stage equation:

$$
S_{i c t}=\alpha_{0}+\alpha_{1} \text { sunset }_{c t}+\alpha_{2} X_{i c t}+\alpha_{3} K_{c t}+\alpha_{4} I_{i c t}+\eta_{r}+v_{i c t}
$$

where sunset $_{c t}$ is the average sunset time in city $c$ at time $t$. To take into account the potential correlation across individuals living in the same city we cluster standard errors at the city level.

Another relevant concern is the quality of the data as we use self-reported measures of sleep (see also Section 3.4). As any self-reported measure, self-reported sleep duration might poorly represent the real sleeping habits (Lauderdale et al., 2008) and introduce large measurement error in the analysis. However, if the measurement error is uncorrelated with our instrument (sunset time), our instrumental variable strategy allows us to obtain consistent estimates of the parameter of interest. Furthermore, in the data used in our analysis (see Section 3.4), the question on sleep duration explicitly asked the respondents to report only the time spent sleeping excluding time spent in bed awake (e.g., watching a movie).

\subsection{Data}

The Chinese Health and Retirement Longitudinal Study (CHARLS) is a nationally representative longitudinal survey of Chinese residents aged 45 and older and their spouses. CHARLES was harmonized with the Health and Retirement Study (HRS). This was meant to guarantee high quality standards and the comparability of results also with the other related ageing surveys such as the English Longitudinal Study of Ageing (ELSA) and the Survey of Health, Ageing and Retirement in Europe (SHARE).

The first national wave of CHARLS was fielded in 2011 and includes about 10,000 households and 17,500 individuals in 126 cities, 150 counties/districts and 450 villages/resident committees. The data includes 28 provinces. The second wave was fielded in $2013 .{ }^{9}$ The survey includes information on demographics, family structure/transfer, health status and functioning, biomarkers, health care and insurance, work, retirement and pension, income and consumption, assets (individual and household), and community level information. ${ }^{10}$ The interview is conducted using a face-to-face computer assisted personal interview (CAPI).

CHARLS contains information on average sleep duration in the last month. Respondents are asked to report how many hours they slept on average over the month preceding the interview. ${ }^{11}$ Using this question we constructed both a linear measure of sleep duration in hours and indicators for whether individuals slept at most six or at least eight hours, or between seven and nine hours. ${ }^{12}$ Yearly average sunset time for Chinese cities was computed using the National Ocean

\footnotetext{
${ }^{9}$ CHARLS adopts multi-stage stratified PPS sampling.

${ }^{10}$ Huang et al. (2013) provide an extensive description of the data.

11 "During the past month, how many hours of actual sleep did you get at night (average hours for one night)?"

${ }^{12}$ Information on sleep duration is missing in $10 \%$ of the sample. To avoid double selection due to the missing
} 
and Atmospheric Administration (NOAA) and the information on the city of residence available in the survey. ${ }^{13}$

Since the sleeping variable in CHARLS measures the self-reported average sleep duration in the last month, in principle, we could also use the average sunset time in the last month preceding the interview as instrument to exploit the seasonal variation in sunset time. Unfortunately, most of the interviews took place in July and August, so we do not have sufficient seasonal variation to exploit. Moreover, since our aim is to evaluate the "long-term" effects of chronic sleep deprivation on cognitive abilities, we believe that the average sunset time should better capture these "longterm" effects than short-term sleep restriction caused by seasonal variation in sunset time.

The CHARLS data contains several questions measuring cognition and depression. In particular, we measure the level of individual cognitive abilities using the result of all cognitive tests available in the survey: Mental, Numerical, TICS, Memorial, and Draw. These tests are administered by interviewers to all respondents (excluding only proxy respondents) and follow a protocol aimed at minimizing the potential influences of the interviewer and the interview process. The questions were adapted from the HRS and are comparable with similar cognitive tests implemented in ELSA and SHARE. The research team of HSR developed the tests based on the literature on intelligence and cognition in psychology and the geriatric and neurological literature on cognitive impairment and dementia, ${ }^{14}$ and the initial evaluation suggested that the response rates, psychometric properties, and construct validity was reasonable (Crimmins et al., 2011; Wallace and Herzog, 1995). These cognitive tests strongly predict important economic outcomes (McArdle et al., 2011) and financial decisions such as portfolio choices (Banks and Oldfield, 2007) and were largely used in the recent literature, especially to analyze the effect of retirement on cognitive abilities in older ages (Bonsang et al., 2012; Mazzonna and Peracchi, 2012).

The Mental test measures the awareness of the date, the day of the week, and the season of the interview to capture the mental intactness of the respondent (McArdle et al., 2011). The score is based on the number of correct answers, ranging from zero to five. The Numerical test measures individual's ability to compute simple mathematical subtractions (successively subtract 7 from 100 for five times). The score is based on the number of correct answers, ranging from zero to five. The Telephone Interview of Cognitive Status, abbreviated to TICS is the sum of the score from Mental test and Numerical test. The TICS test is a well-known indicator that can

responses in both the sleeping and cognitive tests variables, we impute the missing information on sleeping behavior using the standard Stata routine to impute missing variables values and individual information on gender, age, education, employment status, province of residence, rural status of residence, and interview wave. We use Stata command -mi impute- to impute the missing sleeping hours. The imputed sleeping hours used in the regressions is the mean of 20 rounds non-negative imputations. If we exclude individuals with missing information on sleeping, the standard errors become larger and the coefficients are less precisely estimated (see Table A.2), but the point-estimates of first-stage and 2SLS are substantially identical and remain statistically significant in our main sample of employed individuals living in urban areas.

${ }^{13}$ http://www.esrl.noaa.gov/gmd/grad/solcalc/. Accessed on February 20, 2016.

${ }^{14}$ A detailed documentation is available from: http://hrsonline.isr.umich.edu/sitedocs/userg/dr-006.pdf. Accessed on February 20, 2016. 
be administered in person or by telephone - in CHARLS, as mentioned above, the interview is conducted using a face-to-face CAPI - and is highly correlated with the Mini-Mental State Exam (MMSE) (Folstein et al., 1975), a screening tool frequently used by health-care providers to assess overall brain function. The Memorial or Word recall test measures episodic memory (McArdle et al., 2011). Interviewers read a list of 10 nouns to respondents who were asked to recall them immediately as well as 10 minutes later. The score is based on the average number of correct answers during two recall sessions, ranging from zero to ten. Finally, the Draw test examines the ability to redraw a picture of two overlapping pentagons. Respondents score one if the task is successfully performed; zero otherwise.

Following Huang et al. (2013), we also measure individual's depression status by using a Chinese version of the CES-D 10 questionnaire and constructing an indicator ranging from zero to thirty based on the answer of respondents. The higher the CES-D score, the more severe the depression is.

As already mentioned, we restrict our analysis to individuals living in UTC $+7, \mathrm{UTC}+8$, and UTC+9. Note that while Xinjiang, Tibet, part of Gansu and Qinghai provinces are located in $\mathrm{UTC}+5$ and UTC $+6, \mathrm{CHARLS}$ was only fielded in one city (i.e. Aksu from Xinjiang) within this area, where a two-time zone system, i.e. the official "Beijing Time" and the unofficial "Xinjiang Time", is operating (see Section 3.2). ${ }^{15}$ We exclude individuals aged over 70, mostly to avoid selection issues due to the fact that average life expectancy in China is 74 years for men and 77 years for women (WHO, 2013). ${ }^{16}$ Furthermore, since in our main analysis we focus on older workers, the share of individuals over 70 reporting to work is less than $2 \%$ and thus represents a very selected sample of the population. ${ }^{17}$

Table 2 reports summary statistics for all the variables used in the analysis. Column 1 presents the summary statistics for the entire sample. In column 2, we focus on the employed population living in the urban areas, who, as explained above, are those more likely to be affected by social constraints (e.g., work schedules) and, thus, less able to compensate a later bedtime with a later wake-up time (see also Giuntella and Mazzonna, 2015).

It is worth noting that the average sleep duration reported in our sample is less than 6.5 hours. This means that the average sleep duration in China is far below the sufficient number of hours of sleep usually recommended in the literature (between seven and nine hours of sleep, see Cappuccio et al., 2010).

Therefore, according to the results of the experimental literature on partial sleep deprivation surveyed in Section 2, we might expect negative health effects from such sleeping habits.

In Table 3, we report the summary statistics for the employed and urban sample. We perform a balancing test comparing late sunset areas with early sunset areas. Controlling for regional

\footnotetext{
${ }^{15}$ By restricting our sample to areas located in UTC+7, UTC+8, and UTC+9, we dropped 106 and 102 individuals in 2011 and 2013, respectively.

${ }^{16}$ http://www.who.int/countries/chn/en/. Accessed on February 20, 2016.

${ }^{17}$ However, these restrictions do not significantly affect our results. Restricting to individuals below age 60 yields very similar results (available upon request).
} 
fixed effects, individuals living in late sunset areas tend to sleep significantly less than those in early sunset areas, and have poorer cognitive outcomes. There is also evidence of a marginal difference in age as individuals living in early sunset areas tend to be slightly older than those living in late sunset areas. However, most of the other individual covariates are balanced across the two samples and we control for age in all our estimates.

\section{Main Results}

\subsection{First-Stage: Sunset and Sleep}

We first show that the average sunset time has large effects on sleep duration. Second, we show that, consistent with our conjecture, these effects are driven by employed people in urban areas. Their schedules are less flexible than those of the unemployed or less responsive to the daily solar cycle than those of individuals living in rural areas. Table 4 presents estimates of the effect of the average sunset time on sleep duration using different model specifications. In Model A, we include among our controls a large set of individual socio-demographic characteristics (education, i.e. no formal education or illiterate, at most completed elementary school, completed middle school, completed at least high school or vocational school, age and its quadratic term, gender, marital status, Hukou status and birthplace) and interview characteristics (survey wave and month fixed effects). Model B adds to Model A regional fixed effects (see Section 3 and Figure 3) and geographical characteristics that might affect the individual's light exposure (i.e. main landscape and degree of industrial pollution). Model C includes socio-economic characteristics (subjective poverty status, the logarithm of household consumption, the logarithm of population and GDP). Standard errors are clustered at the city level.

The table clearly shows that the average sunset time has significant effects on respondents' self-reported sleep duration. A one hour increase in average sunset time reduces sleep duration by 22 minutes, approximately 0.25 standard deviations (Model A). The estimated effect substantially increases (in absolute terms) to 33 minutes (0.38 standard deviations) when we include economic controls at the city level (Model C). This result is particularly relevant to our analysis for two main reasons. First, it shows that the sunset time is a strong and significant predictor of sleep duration, in particular if we consider that the average sleep duration is roughly 6.5 hours. This is also relevant from a medical perspective because the experimental evidence on sleep deprivation finds the presence of sizeable negative health effects when people are constrained to sleep less than seven hours per night. Second, we show that if we do not account for individual economic characteristics and the level of economic activity (the controls included directly or indirectly in Model B and C), we introduce a downward bias in the estimated effect of the average sunset time on sleep-duration. Along the eastern coast, where the sunset occurs at a earlier nominal hour than in western cities, the level of economic activities is higher and work pressures as well as the digitalization of life (and bedroom), often blamed as important factors of sleep deprivation, are likely to delay individual bedtime, mitigating the positive effect of a early 
sunset on sleep duration (Xiang et al., 2008). In Section 4.4 we also show that Model A does not pass the unconfoundness test on knee height and child health. It is also worth noting that the passage from Model B to Model C does not substantially affects the point estimate but slightly increases the precision of our estimates (see also the F-test at the bottom of the table). For these reasons, we choose Model $\mathrm{C}$ as our baseline model.

In Table 5, we analyze the effect on other subgroups of the population. In particular, we estimate Model C in six different subsamples: rural, urban, employed, not-employed, rural and employed, and again our main sample urban and employed. Overall, our results show that while the coefficient is always negative, it is only statistically significant for respondents living in urban areas and among the employed. Indeed, the largest effect is observed in our main sample. In particular, column 1 shows that in urban areas an hour difference in the average sunset time reduces sleep duration by 14 minutes (column 1). The coefficient is smaller and not statistically significant in rural areas (column 2). Instead, the point-estimate more than doubles when we focus on the employed population (column 3). The coefficient is again small and non-significant when analyzing the non-employed population (column 4). While we find no significant effects in rural areas, where the population is largely comprised by farmers, we do observe a larger pointestimate (column 5) when focusing on individuals employed in other (non-farming) occupations.

Indeed, in Section 4.4 we show that there is no significant effect among the farmers in the CHARLS sample. Our findings confirm our conjecture that farmers are less affected by time zone settings and more likely to follow the natural light in their daily activities and are consistent with recent evidence showing that farmers in China have longer sleep duration and better sleep quality than Chinese employed as blue collar workers or civil servants (Sun et al., 2015). We also find no evidence of significant effects among self-employed (see Section 4.4) who are likely to be more flexible than employed individuals with respect to their work schedules). In Section 4.4, we show that our findings are robust to alternative non-linear measures of sleep duration.

\subsection{Reduced-Form Analysis: Sunset and Cognitive Skills}

Table 6 analyzes the reduced-form relationship between sunset time, a battery of cognitive outcomes and a depression test (CES-D). Each set of rows reports the estimated reduced-form effect on a specific cognitive outcome (along with the number of observations and the R-squared), starting from the mental skills test. The last row reports the estimated effect on the depression test (CES-D). Again, we group the results by urban/rural and employment status.

With the exception of the effect on memorial test for a few subgroups, our point-estimates show that a later sunset time is always negatively associated with the average test score. Consistent with our first-stage results, point-estimates are larger (in both relative and absolute terms) for the employed respondents in urban areas. For this subgroup, an hour increase in the average sunset time is significantly associated with a 0.37 points reduction in mental abilities ( $9 \%$ reduction with respect to the mean), 0.64 points reduction in numerical skills (18\% reduction with respect to the mean), and a one point reduction in the average TICS score (13\% reduction with 
respect to the mean). The estimated effects on Drawn and mental score are rather small and not significantly different from zero.

It is worth noting that, unlike our first-stage results, we found evidence of a significant effect of the average sunset time also among retired people (not-employed). As discussed in Section 2.2, this result should not represent a concern since the estimated reduced-form effect might also capture "long-term" effects of previous sleep deprivation on cognitive abilities. Therefore, we are not surprised to find evidence of an association among retired people, as they used to be exposed to different sunset time when they were employed. However, it is reassuring that the largest effects are found among employed respondents (column 3), especially in urban areas (column 6).

Finally, in the last set of rows we show that a later sunset is associated with a higher depression score among the employed population in urban areas. An hour increase in average sunset time increases the depression score by $19 \%$ with respect to the mean observed in the sample. Note that this is also reassuring that the exposure to daylight is not confounding our analysis through its possible effects on depression symptoms. Indeed, we find, that if anything, an earlier sunset has positive effects on depression (lower CES-D score).

\subsection{SLS Estimates: Sleep Duration and Cognitive Skills}

Having shown the effect of the average sunset time on sleep duration and its reduced-form effect on cognition and mental depression, it is natural to show the 2SLS estimates to provide an estimate of the average effect of one hour of sleep on cognitive abilities and depression symptoms. However, as already discussed throughout the paper, these estimates must be interpreted with caution as they represent the effect of both short and "long-term" effect of sleep deprivation. In particular, while the reduced-form effects capture the effect of long-run exposure to sleep deprivation, the first-stage is based on the short-run effect of average sunset time on sleep duration in the month before the interview.

Table 7 reports 2SLS estimates for the effects of sleep duration on cognitive skills and depression symptoms in our main sample. Focusing on employed individuals in urban areas mitigates the concerns regarding weak instrument problems. Because of the presence of some item nonresponse on cognitive questions, the value of the F-test on the excluded instruments slightly decreases with respect to the value shown in Table 3 going below the value of 10, the Staiger and Stock's (1997) rule of thumb for weak instrument problems (Staiger and Stock, 1997). However, this should not represent a concern for two main reasons. First, as for all values between 8.96 and 16.38, it still corresponds to a maximum 2SLS size distortion of no more than $10 \%$ (see the critical value for weak instrument test in Stock and Yogo, 2005). Second, our estimates pass the Anderson-Rubin test that is robust to weak instrument (Moreira, 2003).

Our 2SLS estimates show that an increase in average sleep duration increases cognitive abilities and lowers the depression symptoms score. Excluding the draw and the memorial test, the estimated effect is always statistically significant at least at the $10 \%$ level. In particular, a 30 
minutes increase in average sleep duration -the sleep variation generated by an hour increase in sunset time (see Table 4)- would increase numerical skills by $16 \%$, the mental test by $9 \%$ and the TICS test by $12 \%$ with respect to the mean of each dependent variable. ${ }^{18}$ To gauge a sense of the magnitude, Huang and Zhou (2013) estimate that concluding primary education increases cognition scores by $20 \%$.

Finally, we find evidence that a 30 minute increase in average sleep duration would reduce the CES-D score by $17.5 \%$ with respect to the mean. This is an economically important effect. Again, to gauge a sense of the magnitude, Lei et al. (2014) show that having completed junior school is associated with a $20 \%$ lower depressive symptom score.

\subsection{Robustness Checks}

In this section, we report the results of a set of tests that we implement to verify the robustness of our estimates and the validity of our identification strategy. We start from Table 8 where we analyze alternative non-linear measures of sleep, such as sleeping no more than six hours, sleeping at least eight hours and between seven and nine hours. These metrics have been often used in the medical literature analyzing sleep deprivation (Cappuccio et al., 2010).

The results are fully consistent with those reported in Table 5. Regardless of the metric considered, a later sunset time has a negative effect on sleeping, in particular if we focus on employed people living in urban areas. More specifically, for employed people living in urban areas, one hour increase in sunset time increases the probability of sleeping less than 6 hours by 14 percentage points (column 1), or decreases the probability of sleeping at least eight hours by 17 percentage points (column 2).

We also indirectly test our identification assumption by verifying whether the average sunset is significantly associated with other predetermined characteristics that should not be affected by a different sunset time. In Table 9, we test the association of the average sunset time with the individuals' knee height and self-reported poor health during childhood. The lower leg length is not correlated with height shrinkage that may be affected by adult life-style behaviors and more likely to reflect predetermined anthropometric characteristics (Maurer, 2010; Roubenoff and Wilson, 1993). We use the same specification (Model C), we used to analyze the effect of the average sunset time on sleep duration. The results clearly show that there is no evidence of any significant effect of the average sunset time on these two variables. This is reassuring because a significant correlation with predetermined characteristics would cast doubts on our identification strategy. Different is the evidence when we run the same test using Model A instead of Model C. Indeed, the results reported in Table A.3 show that average sunset time is significantly associated with the two predetermined characteristics. This clearly suggests that, in our setting, is crucial to account for the geographical and economic characteristics of the respondents' location.

\footnotetext{
${ }^{18}$ Using an overall measure of respondents' cognitive function (0-21), which sums the scored obtained in TICS test, the word recall test, and the draw test, we find that an hour increase in sleep duration would increase the overall cognitive score by $30 \%$ with respect to the mean of the dependent variable (results are available upon request).
} 
As mentioned above, we also test whether sleeping behavior, cognitive skills and depression symptoms of farmers and self-employed are affected by variation in sunset time. Table 11 shows that the effects are non-significant and smaller in magnitude among farmers (despite the large sample size). Similarly, we do not find evidence of significant effects when we focus on selfemployed in urban areas. Given the low sample size and the rather large standard errors we cannot conclude that this group is not affected at all. However, point-estimates are far smaller than those found among employed people, suggesting that self-employed have more flexible schedules, so that they can, at least partially, compensate the effect of the large differences in sunset time across Chinese cities.

Our results are not driven by one particular province. When we replicate all our estimates by leaving out one province at a time, the results hold and remain consistent with those reported in the main text (available upon request). Finally, using the retrospective questions of the survey we are able to recover individual's migration history. Our findings are substantially unchanged if we exclude individuals who were born in a different province or individuals who reported working in a different province. This is not surprising as we focus on individuals aged over 45. Internal migration was long restricted by the Hukou system, which began to loosen only in the mid 80's in response to the demands of both the market and rural residents wishing to seek greater economic opportunity in cities (Au and Henderson, 2006).

\section{Conclusions}

Economists have largely ignored the effects of sleep on health and human capital. The medical literature provides extensive evidence of the association between sleep deprivation and health. However, most of these studies do not attempt to analyze the causal relationship between sleep duration and health outcomes. Furthermore, we know relatively little about the effects of sleep duration on cognitive skills in developing contexts. However, in many low- and middle-income countries sleep deprivation is becoming increasingly recognized as a public health challenge, particularly because of its effects on the elderly population.

In this paper we analyze the effects of sleep duration on the cognitive skills of older workers in China. We show that sleep duration has non-trivial effects on cognitive and mental skills. To identify the effects of sleep on cognitive skills, we use an instrumental variable that exploits the relationship between sunset time, circadian rhythms, and average sleep duration. Our findings indicate that an increase in average sleep duration increases significantly old age cognitive skills and reduces the depression symptoms score. We find no evidence of significant effects on memorial and drawing skills. The effects are larger among employed individuals in urban areas and robust to the use of non-linear metrics of sleep duration. Importantly, a later sunset does not have significant effects on outcomes that are not affected by sleep duration.

Our results suggest that increasing the awareness of the negative effects of sleep deprivation is crucial for the design of policies aimed at reducing the cognitive decline associated with ageing. 
Increasing the attention on the importance of sleep quality may have non-trivial effects on both cognitive skills and mental health of older workers. 


\section{References}

Alhola, P., Polo-Kantola, P., 2007. Sleep deprivation: impact on cognitive performance. Neuropsychiatric Disease and Treatment 3 (5), 553.

Aschoff, J., Fatranska, M., Giedke, H., Doerr, P., Stamm, D., Wisser, H., 1971. Human circadian rhythms in continuous darkness: entrainment by social cues. Science 171 (3967), 213-215.

Au, C.-C., Henderson, J. V., 2006. How migration restrictions limit agglomeration and productivity in China. Journal of Development Economics 80 (2), 350-388.

Banks, J., Oldfield, Z., 2007. Understanding pensions: cognitive function, numerical ability and retirement saving. Fiscal studies 28 (2), 143-170.

Banks, S., Dinges, D. F., 2011. Chapter 6 - chronic sleep deprivation. In: Dement, M. H. K. R. C. (Ed.), Principles and Practice of Sleep Medicine (Fifth Edition). W.B. Saunders, Philadelphia, pp. $67-75$.

Barnes, C. M., Wagner, D. T., 2009. Changing to daylight saving time cuts into sleep and increases workplace injuries. Journal of Applied Psychology 94 (5), 1305.

Benito-León, J., Bermejo-Pareja, F., Vega, S., Louis, E. D., 2009. Total daily sleep duration and the risk of dementia: a prospective population-based study. European Journal of Neurology 16 (9), 990-997.

Biddle, J. E., Hamermesh, D. S., 1990. Sleep and the allocation of time. Journal of Political Economy $98,922-943$.

Bonke, J., 2012. Do morning-type people earn more than evening-type people? how chronotypes influence income. Annals of Economics and Statistics 105/106, 55-72.

Bonsang, E., Adam, S., Perelman, S., 2012. Does retirement affect cognitive functioning? Journal of health economics 31 (3), 490-501.

Cappuccio, F. P., D’Elia, L., Strazzullo, P., Miller, M. A., 2010. Sleep duration and all-cause mortality: a systematic review and meta-analysis of prospective studies. Sleep 33 (5), 585.

Carrell, S. E., Maghakian, T., West, J. E., 2011. A's from zzzz's? the causal effect of school start time on the academic achievement of adolescents. American Economic Journal: Economic Policy 3 (3), 62-81.

Chan, K. W., Zhang, L., 1999. The hukou system and rural-urban migration in China: Processes and changes. The China Quarterly 160, 818-855. 
Crimmins, E. M., Kim, J. K., Langa, K. M., Weir, D. R., 2011. Assessment of cognition using surveys and neuropsychological assessment: the Health and Retirement Study and the Aging, Demographics, and Memory Study. The Journals of Gerontology Series B: Psychological Sciences and Social Sciences 66 (suppl 1), i162-i171.

Cutler, D. M., Lleras-Muney, A., Vogl, T., 2011. Socioeconomic status and health: dimensions and mechanisms. In: Oxford Handbook of Health Economics. Oxford University Press.

Dinges, D. F., 1995. An overview of sleepiness and accidents. Journal of Sleep Research 4 (s2), $4-14$.

Duffy, J. F., Wright, K. P., 2005. Entrainment of the human circadian system by light. Journal of Biological Rhythms 20 (4), 326-338.

Edwards, F., 2012. Early to rise? the effect of daily start times on academic performance. Economics of Education Review 31 (6), 970-983.

Gibson, M., Shrader, J., 2014. Time use and productivity: the wage returns to sleep.

URL http://econweb.ucsd.edu/ magibson/pdfs/sleep_productivity.pdf

Gildner, T. E., Liebert, M. A., Kowal, P., Chatterji, S., Snodgrass, J. J., 2014. Associations between sleep duration, sleep quality, and cognitive test performance among older adults from six middle income countries: Results from the study on global ageing and adult health (SAGE). Journal of Clinical Sleep Medicine 10 (6), 613.

Gilley, B., 2004. China's democratic future: How it will happen and where it will lead. Columbia University Press.

Giuntella, O., Mazzonna, F., 2015. If you don't snooze you lose health and gain weight. Tech. rep., Università della Svizzera italiana.

Hahn, E. A., Wang, H.-X., Andel, R., Fratiglioni, L., 2014. A change in sleep pattern may predict alzheimer disease. American Journal of Geriatric Psychiatry 22 (11), 1262 - 1271, physical Comorbidity.

Hamermesh, D. S., Myers, C. K., Pocock, M. L., 2008. Cues for timing and coordination: latitude, letterman, and longitude. Journal of Labor Economics 26 (2), 223-246.

Hanushek, E. A., Woessmann, L., 2008. The role of cognitive skills in economic development. Journal of economic literature, 607-668.

Huang, W., Lei, X., Ridder, G., Strauss, J., Zhao, Y., 2013. Health, height, height shrinkage, and SES at older ages: evidence from China. American Economic Journal: Applied Economics 5 (2), 86-121. 
Huang, W., Zhou, Y., 2013. Effects of education on cognition at older ages: evidence from China's Great Famine. Social Science \& Medicine 98, 54-62.

Jin, L., Ziebarth, N. R., 2015. Does daylight saving time really make us sick? Tech. rep., IZA Discussion Papers.

Kamstra, M. J., Kramer, L. A., Levi, M. D., 2000. Losing sleep at the market: the daylight saving anomaly. American Economic Review, 1005-1011.

Killgore, W., 2010. Effects of sleep deprivation on cognition. Human Sleep and Cognition: Basic Research 185.

Kjærgaard, M., Waterloo, K., Wang, C. E., Almås, B., Figenschau, Y., Hutchinson, M. S., Svartberg, J., Jorde, R., 2012. Effect of vitamin d supplement on depression scores in people with low levels of serum 25-hydroxyvitamin D: nested case-control study and randomised clinical trial. British Journal of Psychiatry 201 (5), 360-368.

Lauderdale, D. S., Knutson, K. L., Yan, L. L., Liu, K., Rathouz, P. J., 2008. Self-reported and measured sleep duration: how similar are they? Epidemiology 19 (6), 838-845.

Lei, X., Hu, Y., McArdle, J. J., Smith, J. P., Zhao, Y., 2012. Gender differences in cognition among older adults in China. Journal of Human Resources 47 (4), 951-971.

Lei, X., Sun, X., Strauss, J., Zhang, P., Zhao, Y., 2014. Depressive symptoms and SES among the mid-aged and elderly in China: evidence from the China Health and Retirement Longitudinal Study national baseline. Social Science \& Medicine 120, 224-232.

Li, S., Jin, X., Wu, S., Jiang, F., Yan, C., Shen, X., 2007. The impact of media use on sleep patterns and sleep disorders among school-aged children in China. Sleep 30 (3), 361.

Luo, J., Zhu, G., Zhao, Q., Guo, Q., Meng, H., Hong, Z., Ding, D., 2013. Prevalence and risk factors of poor sleep quality among Chinese elderly in an urban community: results from the shanghai aging study. PloS one 8 (11), e81261.

Maurer, J., 2010. Height, education and later-life cognition in Latin America and the Caribbean. Economics \& Human Biology 8 (2), 168-176.

Mazzonna, F., Peracchi, F., 2012. Ageing, cognitive abilities and retirement. European Economic Review 56 (4), 691-710.

McArdle, J. J., Smith, J. P., Willis, R., 2011. Cognition and economic outcomes in the health and retirement survey. In: Explorations in the Economics of Aging. University of Chicago Press, pp. 209-233.

Monk, T. H., 2012. Sleep and human performance. The Oxford Handbook of Sleep and Sleep Disorders, 95. 
Moreira, M. J., 2003. A conditional likelihood ratio test for structural models. Econometrica 71 (4), 1027-1048.

Owens, J. A., Belon, K., Moss, P., 2010. Impact of delaying school start time on adolescent sleep, mood, and behavior. Archives of Pediatrics \& Adolescent Medicine 164 (7), 608-614.

Pan, F., 2004. Confucian culture and modernization in China. Journal of Hubei Normal University $64(6)$.

Roenneberg, T., 2013. Chronobiology: the human sleep project. Nature 498 (7455), 427-428.

Roenneberg, T., Kuehnle, T., Juda, M., Kantermann, T., Allebrandt, K., Gordijn, M., Merrow, M., 2007. Epidemiology of the human circadian clock. Sleep Medicine Reviews 11 (6), 429-438.

Roenneberg, T., Merrow, M., 2007. Entrainment of the human circadian clock. In: Cold Spring Harbor Symposia on Quantitative Biology. Vol. 72. Cold Spring Harbor Laboratory Press, pp. 293-299.

Roubenoff, R., Wilson, P., 1993. Advantage of knee height over height as an index of stature in expression of body composition in adults. American journal of clinical nutrition 57 (5), 609-613.

Smith, A. C., forthcoming. Spring forward at your own risk: daylight saving time and fatal vehicle crashes. American Economic Journal: Applied Economics.

Sood, N., Ghosh, A., 2007. The short and long run effects of daylight saving time on fatal automobile crashes. The B.E. Journal of Economic Analysis \& Policy 7 (1).

Spiegel, K., Leproult, R., Van Cauter, E., 1999. Impact of sleep debt on metabolic and endocrine function. The Lancet 354 (9188), 1435-1439.

Staiger, D., Stock, J. H., 1997. Instrumental variables regression with weak instruments. Econometrica: Journal of the Econometric Society, 557-586.

Stewart, J., 2014. Early to bed and earlier to rise: school, maternal employment, and childrens sleep. Review of Economics of the Household 12 (1), 29-50.

Stock, J., Yogo, M., 2005. Testing for Weak Instruments in Linear IV Regression. In: D.W.K. Andrews, Identification and Inference for Econometric Models. Cambridge University Press, New York, pp. 80-108.

Stranges, S., Tigbe, W., Gomez-Olive, F. X., Thorogood, M., Kandala, N.-B., 2012. Sleep problems: an emerging global epidemic? findings from the INDEPTH WHO-SAGE study among more than 40,000 older adults from 8 countries across Africa and Asia. Sleep 35 (8), 1173-1181.

Sun, W., Yu, Y., Yuan, J., Li, C., Liu, T., Lin, D., Lau, A., Zhong, C., Xu, T., Shan, G., 2015. Sleep duration and quality among different occupations-China national study. PloS one 10 (3), e0117700. 
Tsuno, N., Besset, A., Ritchie, K., 2005. Sleep and depression. Journal of Clinical Psychiatry 66 (10), 1254-1269.

Van Dongen, H. P., Maislin, G., Mullington, J. M., Dinges, D. F., 2003. The cumulative cost of additional wakefulness: dose-response effects on neurobehavioral functions and sleep physiology from chronic sleep restriction and total sleep deprivation. Sleep 26 (2), 117-129.

Van Someren, E., 2000. Circadian and sleep disturbances in the elderly. Experimental gerontology 35 (9), 1229-1237.

Wallace, R. B., Herzog, A. R., 1995. Overview of the health measures in the Health and Retirement Study. Journal of Human Resources, S84-S107.

Wirz-Justice, A., Van den Hoofdakker, R. H., 1999. Sleep deprivation in depression: what do we know, where do we go? Biological psychiatry 46 (4), 445-453.

Wittmann, M., Dinich, J., Merrow, M., Roenneberg, T., 2006. Social jetlag: misalignment of biological and social time. Chronobiology International 23 (1-2), 497-509.

Xiang, Y.-T., Ma, X., Cai, Z.-J., Li, S.-R., Xiang, Y.-Q., Guo, H.-L., Hou, Y.-Z., Li, Z.-B., Li, Z.-J., Tao, Y.-F., et al., 2008. The prevalence of insomnia, its sociodemographic and clinical correlates, and treatment in rural and urban regions of Beijing, China: a general population-based survey. Sleep 31 (12), 1655.

Yaffe, K., Falvey, C. M., Hoang, T., 2014. Connections between sleep and cognition in older adults. Lancet Neurology 13 (10), 1017 - 1028. 
Table 1: Population and GDP, by UCT Time Zones in 2013

\begin{tabular}{lcccc}
\hline \hline Time zone: & UTC +5 and +6 & UTC +7 & UTC +8 & UTC +9 \\
\hline GDP & $1.91 \%$ & $30.57 \%$ & $65.41 \%$ & $2.11 \%$ \\
Population & $2.61 \%$ & $38.36 \%$ & $56.62 \%$ & $2.42 \%$ \\
\hline \hline
\end{tabular}

Notes - GDP and population data at province level are drawn from China Statistical Yearbook (2014), excluding Hong Kong SAR, Macao SAR and Taiwan. Although most provinces lie within a single geographical time zones, there are 10 out of 31 provinces that are divided into two time zones. Therefore, the aggregated GDP and population by time zone are calculated by authors roughly according to the proportion of territory located in each time zone. The details are as follows: Jilin and Heilongjiang are split equally between UTC+8 and UTC+9; Shanxi, Inner Mongolia, Henan, Hubei, and Guangdong are split equally between UTC +7 and UTC+8; Qinghai is split equally between UTC +6 and UTC +7 ; two-third of Hunan is counted in UTC +7 and the rest in UTC +8 ; one-fourth of Gansu is counted in UTC+6 and the rest in UTC+7. 
Table 2: Summary Statistics

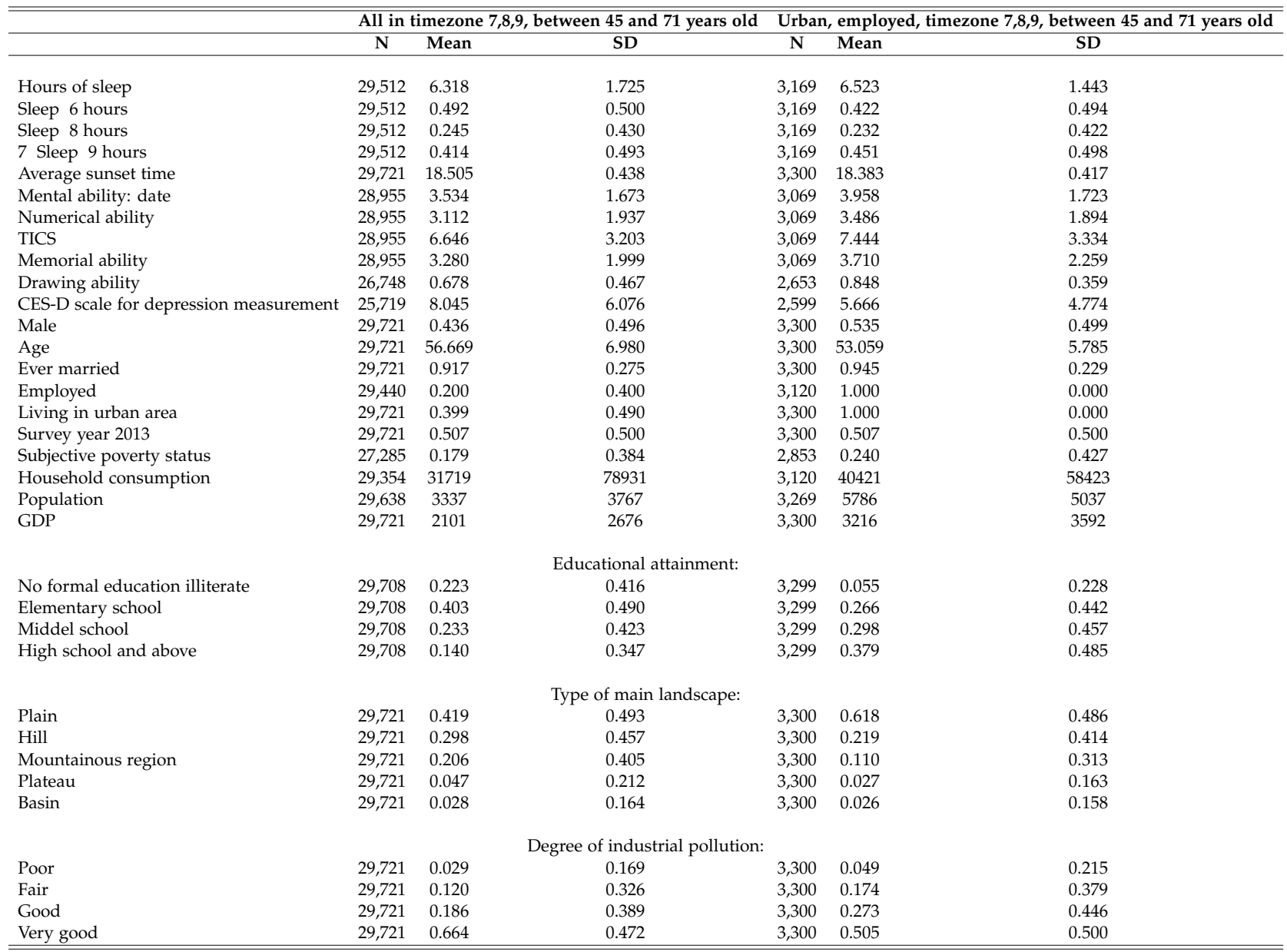

Notes - Data are drawn from the China Health and Retirement Longitudinal Study (CHARLS, 2011-2013) except GDP of the residential city that are draw from Statistical Yearbook of each provinces $(2011,2013)$. The summary statistics are not weighted. 
Table 3: Balancing Test, Individual Characteristics

\begin{tabular}{lccccc}
\hline \hline & \multicolumn{3}{c}{ Early sunset } & \multicolumn{3}{c}{ Late sunset } & t-test \\
& N & Mean & N & Mean & \\
\hline & & & & & \\
Hours of sleep & 1473 & 6.633 & 1163 & 6.411 & -4.015 \\
Sleep 6 hours & 1473 & 0.394 & 1163 & 0.453 & 2.840 \\
Sleep 8 hours & 1473 & 0.258 & 1163 & 0.200 & -4.699 \\
7 Sleep 9 hours & 1473 & 0.492 & 1163 & 0.409 & -2.158 \\
Average sunset time & 1473 & 18.089 & 1163 & 18.732 & 9.258 \\
Mental ability: date & 1422 & 4.092 & 1108 & 4.008 & 1.186 \\
Numerical ability & 1422 & 3.653 & 1108 & 3.508 & -1.665 \\
TICS & 1422 & 7.745 & 1108 & 7.516 & -0.336 \\
Memorial ability & 1422 & 3.851 & 1108 & 3.721 & 0.467 \\
Drawing ability & 1266 & 0.845 & 981 & 0.842 & 0.007 \\
CES-D scale for depression measurement & 1237 & 5.290 & 961 & 6.057 & -0.801 \\
Male & 1473 & 0.614 & 1163 & 0.618 & -1.367 \\
Age & 1473 & 53.365 & 1163 & 52.770 & -2.826 \\
Educational attainment & 1473 & 2.983 & 1163 & 3.028 & 0.579 \\
Ever married & 1473 & 0.947 & 1163 & 0.963 & -0.620 \\
Subjective poverty status & 1473 & 0.257 & 1163 & 0.201 & 0.487 \\
Household consumption & 1473 & 40242.308 & 1163 & 41233.878 & 0.421 \\
\hline \hline
\end{tabular}

Notes - Data are drawn from the China Health and Retirement Longitudinal Study (CHARLS, 2011-2013). The sample is restricted to employed individuals living in the urban area of time zone 7, 8 or 9, between 45 and 70 years old and weighted using individual survey weights. T-test: the estimates include survey wave and regional fixed effects. Standard errors are clustered at city level. Late sunset: sunset time of a city is above the median of all cities' sunset time. 
Table 4: First Stage: Sunset Time and Sleep Duration for Employed People in Urban Areas (Models Comparison)

\begin{tabular}{|c|c|c|c|}
\hline $\begin{array}{l}\text { Dependent Variable: } \\
\text { Model: }\end{array}$ & $\begin{array}{c}(1) \\
\text { Sleep hours } \\
\text { A }\end{array}$ & $\begin{array}{c}(2) \\
\text { Sleep hours } \\
\text { B }\end{array}$ & $\begin{array}{c}\text { (3) } \\
\text { Sleep hours } \\
\text { C }\end{array}$ \\
\hline Average sunset time & $\begin{array}{l}-0.358^{* * *} \\
(0.098)\end{array}$ & $\begin{array}{l}-0.602^{* * *} \\
(0.186)\end{array}$ & $\begin{array}{l}-0.555^{* * *} \\
(0.172)\end{array}$ \\
\hline Individual controls & Yes & Yes & Yes \\
\hline Region F.E. & No & Yes & Yes \\
\hline City characteristics & No & No & Yes \\
\hline Observations & 2,636 & 2,636 & 2,636 \\
\hline R-squared & 0.042 & 0.049 & 0.054 \\
\hline Mean of Dep. Var. & 6.535 & 6.535 & 6.535 \\
\hline Std. Dev. of Dep. Var. & 1.425 & 1.425 & 1.425 \\
\hline F-test ${ }^{\dagger}$ & 13.69 & 10.63 & 10.73 \\
\hline
\end{tabular}

Notes - Data are drawn from the China Health and Retirement Longitudinal Study (CHARLS, 2011-2013). Model A include individual controls for education (no formal education or illiterate, at most completed elementary school, completed middle school, completed at least high school or vocational school), age and its quadratic term, gender, marital status, living in urban or rural area, current Hukou location and birth place province (whether different from the current province), and interview characteristics (survey wave and month fixed effects). Model B adds to model A regional fixed effects and two geographical controls, namely type of main landscape (plain, hill, mountain, plateau, basin) and degree of industrial pollution (poor, fair, good, very good). Model C adds to model B individual or household economic characteristics: employment status, subjective poverty status, the logarithm of household consumption, and city characteristics namely the logarithm of GDP and population. The sample is restricted to employed individuals living in the urban area of time zone 7, 8 or 9, between 45 and 70 years old. The estimation sample is weighted using individual weights. Significance levels: ${ }^{* *} p<0.01,{ }^{* *} p<0.05,{ }^{*} p<0.1$. Standard errors are clustered at the city level.

${ }^{\dagger} \mathrm{F}$-test on the excluded instrument. 
Table 5: First Stage: Sunset Time and Sleep Duration by Urban Area and Employment Status

\begin{tabular}{|c|c|c|c|c|c|c|}
\hline $\begin{array}{l}\text { Dependent variable: } \\
\text { Sample: }\end{array}$ & $\begin{array}{c}(1) \\
\text { Sleep hours } \\
\text { Urban }\end{array}$ & $\begin{array}{c}(2) \\
\text { Sleep hours } \\
\text { Rural } \\
\end{array}$ & $\begin{array}{c}(3) \\
\text { Sleep hours } \\
\text { Employed }\end{array}$ & $\begin{array}{c}(4) \\
\text { Sleep hours } \\
\text { Not-employed }\end{array}$ & $\begin{array}{c}(5) \\
\text { Sleep hours } \\
\text { Rural \& emp. }\end{array}$ & $\begin{array}{c}\text { (6) } \\
\text { Sleep hours } \\
\text { Urban \& emp. }\end{array}$ \\
\hline Average sunset time & $\begin{array}{l}-0.229 * * \\
(0.093)\end{array}$ & $\begin{array}{l}-0.118 \\
(0.108)\end{array}$ & $\begin{array}{c}-0.420^{* * *} \\
(0.132)\end{array}$ & $\begin{array}{l}-0.148 \\
(0.094)\end{array}$ & $\begin{array}{l}-0.263 \\
(0.177)\end{array}$ & $\begin{array}{c}-0.555^{* * *} \\
(0.172)\end{array}$ \\
\hline $\begin{array}{l}\text { Observations } \\
\text { R-squared }\end{array}$ & $\begin{array}{c}10,090 \\
0.043\end{array}$ & $\begin{array}{c}16,135 \\
0.034\end{array}$ & $\begin{array}{l}5,062 \\
0.046\end{array}$ & $\begin{array}{c}21,163 \\
0.028\end{array}$ & $\begin{array}{l}2,426 \\
0.058\end{array}$ & $\begin{array}{l}2,636 \\
0.054\end{array}$ \\
\hline $\begin{array}{l}\text { Mean of Dep. Var. } \\
\text { Std.Dev. of Dep. Var. }\end{array}$ & $\begin{array}{l}6.337 \\
1.625\end{array}$ & $\begin{array}{l}6.288 \\
1.808\end{array}$ & $\begin{array}{l}6.540 \\
1.423\end{array}$ & $\begin{array}{l}6.252 \\
1.803\end{array}$ & $\begin{array}{l}6.545 \\
1.421\end{array}$ & $\begin{array}{l}6.535 \\
1.425\end{array}$ \\
\hline
\end{tabular}

Notes - Data are drawn from the China Health and Retirement Longitudinal Study (CHARLS, 2011-2013). All estimates include the same controls as in Model C of Table 4. The sample is restricted to individuals living in time zone 7, 8 or 9, between 45 and 70 years old. The estimated sample is weighted using individual survey weights. Significance levels: ${ }^{* * *} p<0.01,{ }^{* *} p<0.05,{ }^{*} p<0.1$. Standard errors are clustered at the city level. 
Table 6: Reduced-Form Analysis: Sunset Time and Cognitive Skills

\begin{tabular}{|c|c|c|c|c|c|c|}
\hline Sample: & $\begin{array}{c}(1) \\
\text { Urban }\end{array}$ & $\begin{array}{c}(2) \\
\text { Rural } \\
\end{array}$ & $\begin{array}{c}(3) \\
\text { Employed }\end{array}$ & $\begin{array}{c}(4) \\
\text { Not-employed }\end{array}$ & $\begin{array}{c}\text { (5) } \\
\text { Rural \& emp. }\end{array}$ & $\begin{array}{c}\text { (6) } \\
\text { Urban \& emp. }\end{array}$ \\
\hline Mental & $\begin{array}{l}-0.196 \\
(0.126)\end{array}$ & $\begin{array}{l}-0.145 \\
(0.144)\end{array}$ & $\begin{array}{l}-0.158 \\
(0.195)\end{array}$ & $\begin{array}{l}-0.163 \\
(0.113)\end{array}$ & $\begin{array}{c}0.101 \\
(0.303)\end{array}$ & $\begin{array}{l}-0.371^{* *} \\
(0.170)\end{array}$ \\
\hline $\begin{array}{l}\text { Observations } \\
\text { R-squared }\end{array}$ & $\begin{array}{l}9,884 \\
0.135\end{array}$ & $\begin{array}{c}15,884 \\
0.155\end{array}$ & $\begin{array}{l}4,873 \\
0.121\end{array}$ & $\begin{array}{c}20,895 \\
0.198\end{array}$ & $\begin{array}{l}2,343 \\
0.120\end{array}$ & $\begin{array}{l}2,530 \\
0.099\end{array}$ \\
\hline $\begin{array}{l}\text { Dependent variable: } \\
\text { Numerical }\end{array}$ & $\begin{array}{c}-0.287^{* * *} \\
(0.106)\end{array}$ & $\begin{array}{l}-0.229 * * \\
(0.111)\end{array}$ & $\begin{array}{c}-0.490^{* * *} \\
(0.148)\end{array}$ & $\begin{array}{l}-0.258^{* * *} \\
(0.0853)\end{array}$ & $\begin{array}{l}-0.326 \\
(0.304)\end{array}$ & $\begin{array}{c}-0.636^{* * *} \\
(0.120)\end{array}$ \\
\hline $\begin{array}{l}\text { Observations } \\
\text { R-squared }\end{array}$ & $\begin{array}{l}9,884 \\
0.143\end{array}$ & $\begin{array}{c}15,884 \\
0.223\end{array}$ & $\begin{array}{l}4,873 \\
0.118\end{array}$ & $\begin{array}{c}20,895 \\
0.226\end{array}$ & $\begin{array}{l}2,343 \\
0.130\end{array}$ & $\begin{array}{l}2,530 \\
0.133\end{array}$ \\
\hline $\begin{array}{l}\text { Dependent variable: } \\
\text { TICS }\end{array}$ & $\begin{array}{c}-0.483^{* * *} \\
(0.181)\end{array}$ & $\begin{array}{l}-0.374^{*} \\
(0.221)\end{array}$ & $\begin{array}{l}-0.648^{* *} \\
(0.324)\end{array}$ & $\begin{array}{c}-0.422^{* * *} \\
(0.148)\end{array}$ & $\begin{array}{l}-0.225 \\
(0.571)\end{array}$ & $\begin{array}{l}-1.007^{* * *} \\
(0.263)\end{array}$ \\
\hline $\begin{array}{l}\text { Observations } \\
\text { R-squared }\end{array}$ & $\begin{array}{l}9,884 \\
0.165\end{array}$ & $\begin{array}{c}15,884 \\
0.238\end{array}$ & $\begin{array}{l}4,873 \\
0.125\end{array}$ & $\begin{array}{c}20,895 \\
0.268\end{array}$ & $\begin{array}{l}2,343 \\
0.139\end{array}$ & $\begin{array}{l}2,530 \\
0.114\end{array}$ \\
\hline $\begin{array}{l}\text { Dependent variable: } \\
\text { Memorial }\end{array}$ & $\begin{array}{c}0.232 \\
(0.166)\end{array}$ & $\begin{array}{l}0.0383 \\
(0.162)\end{array}$ & $\begin{array}{l}-0.118 \\
(0.203)\end{array}$ & $\begin{array}{c}0.162 \\
(0.126)\end{array}$ & $\begin{array}{l}-0.399 \\
(0.368)\end{array}$ & $\begin{array}{l}-0.103 \\
(0.216)\end{array}$ \\
\hline $\begin{array}{l}\text { Observations } \\
\text { R-squared }\end{array}$ & $\begin{array}{l}9,884 \\
0.133\end{array}$ & $\begin{array}{c}15,884 \\
0.106\end{array}$ & $\begin{array}{l}4,873 \\
0.136\end{array}$ & $\begin{array}{c}20,895 \\
0.125\end{array}$ & $\begin{array}{l}2,343 \\
0.112\end{array}$ & $\begin{array}{l}2,530 \\
0.153\end{array}$ \\
\hline $\begin{array}{l}\text { Dependent variable: } \\
\text { Draw }\end{array}$ & $\begin{array}{c}-0.006 \\
(0.0324)\end{array}$ & $\begin{array}{c}-0.041 \\
(0.0313)\end{array}$ & $\begin{array}{c}-0.010 \\
(0.0289)\end{array}$ & $\begin{array}{c}-0.038 \\
(0.0264)\end{array}$ & $\begin{array}{c}0.068 \\
(0.0462)\end{array}$ & $\begin{array}{c}-0.041 \\
(0.0348)\end{array}$ \\
\hline $\begin{array}{l}\text { Observations } \\
\text { R-squared }\end{array}$ & $\begin{array}{l}9,208 \\
0.187\end{array}$ & $\begin{array}{c}14,881 \\
0.224\end{array}$ & $\begin{array}{l}4,170 \\
0.182\end{array}$ & $\begin{array}{c}19,919 \\
0.227\end{array}$ & $\begin{array}{l}1,923 \\
0.175\end{array}$ & $\begin{array}{l}2,247 \\
0.198\end{array}$ \\
\hline $\begin{array}{l}\text { Dependent variable: } \\
\text { CES-D }\end{array}$ & $\begin{array}{c}0.189 \\
(0.677)\end{array}$ & $\begin{array}{c}0.693 \\
(0.458)\end{array}$ & $\begin{array}{c}0.875 \\
(0.617)\end{array}$ & $\begin{array}{c}0.727 \\
(0.483)\end{array}$ & $\begin{array}{c}0.613 \\
(1.015)\end{array}$ & $\begin{array}{l}1.199^{*} \\
(0.721)\end{array}$ \\
\hline $\begin{array}{l}\text { Observations } \\
\text { R-squared }\end{array}$ & $\begin{array}{l}8,949 \\
0.129\end{array}$ & $\begin{array}{c}14,227 \\
0.123\end{array}$ & $\begin{array}{l}4,054 \\
0.140\end{array}$ & $\begin{array}{c}19,122 \\
0.110\end{array}$ & $\begin{array}{l}1,856 \\
0.141\end{array}$ & $\begin{array}{l}2,198 \\
0.139\end{array}$ \\
\hline
\end{tabular}

Notes - Data are drawn from the China Health and Retirement Longitudinal Study (CHARLS, 2011-2013). All estimates include the same controls as in Model C of Table 4. The sample is restricted to individuals living in time zone 7, 8 or 9, between 45 and 70 years old. The estimated sample is weighted using individual survey weights. Significance levels: ${ }^{* * *} p<0.01,{ }^{* *} p<0.05,{ }^{*} p<0.1$. Standard errors are clustered at the city level. 
Table 7: 2SLS: Sleeping Time and Cognitive Skills (Urban and Employed)

\begin{tabular}{lcccccc}
\hline \hline & $(1)$ & $(2)$ & $(3)$ & $(4)$ & $(5)$ & $(6)$ \\
Dependent variable: & Mental & Numerical & TICS & Memorial & Draw & CES-D \\
\hline Sleep hours & & & & & & \\
& $0.690^{*}$ & $1.184^{* * *}$ & $1.874^{* *}$ & 0.191 & 0.0675 & $-2.116^{*}$ \\
& $(0.400)$ & $(0.439)$ & $(0.793)$ & $(0.397)$ & $(0.0555)$ & $(1.227)$ \\
Observations & & & & & & \\
F-test $^{\dagger}$ & 2,530 & 2,530 & 2,530 & 2,530 & 2,247 & 2,198 \\
Anderson-Rubin Wald test (p-value) & 9.15 & 9.15 & 9.15 & 9.15 & 9.56 & 8.57 \\
& 0.032 & 0.000 & 0.000 & 0.631 & 0.244 & 0.097 \\
Mean of Dep. Var. & 4.055 & 3.59 & 7.645 & 3.794 & 0.844 & 5.626 \\
Std.Dev. of Dep. Var. & 1.636 & 1.83 & 3.168 & 2.21 & 0.363 & 4.787 \\
\hline \hline
\end{tabular}

Notes - Data are drawn from the China Health and Retirement Longitudinal Study (CHARLS, 2011-2013). All estimates include the same controls as in Model C of Table 4. The sample is restricted to employed individuals living in the urban area of time zone 7, 8 or 9 , between 45 and 70 years old. The estimated sample is weighted using individual survey weights. Significance levels: ${ }^{* * *} p<$ $0.01,{ }^{* *} p<0.05,{ }^{*} p<0.1$. Standard errors are clustered at the city level.

${ }^{\dagger}$ F-test on the excluded instrument. 
Table 8: First Stage: Sunset Time and Other Sleep Measures

\begin{tabular}{lccc}
\hline \hline & $(1)$ & $(2)$ & $(3)$ \\
Dependent variable: & Sleep $\leq 6$ hours & Sleep $\geq 8$ hours & $7 \leq$ Sleep $\leq 9$ hours \\
\hline Average sunset time & $0.178^{* * *}$ & $-0.166^{* * *}$ & $-0.200^{* * *}$ \\
& $(0.063)$ & $(0.043)$ & $(0.069)$ \\
Observations & & & \\
R-squared & 2,636 & 2,636 & 2,636 \\
& 0.093 & 0.087 & 0.090 \\
Mean of Dep. Var. & 0.420 & 0.233 & 0.455 \\
Std.Dev. of Dep. Var. & 0.494 & 0.423 & 0.498 \\
\hline \hline
\end{tabular}

Notes - Data are drawn from the China Health and Retirement Longitudinal Study (CHARLS, 2011-2013). All estimates include the same controls as in Model C of Table 4. The sample is restricted to employed individuals living in the urban area of time zone 7 , 8 or 9 , between 45 and 70 years old. The estimated sample is weighted individual survey weights. Significance levels: $* * * p<0.01$, ${ }^{* *} p<0.05,{ }^{*} p<0.1$. Standard errors are clustered at the city level. 
Table 9: Unconfoundness Test: Sunset Time effect on Knee Height and Self-Reported Child Poor Health

\begin{tabular}{lcccc}
\hline \hline $\begin{array}{l}\text { Dependent variable: } \\
\text { Sample: }\end{array}$ & $\begin{array}{c}(1) \\
\text { Knee height } \\
\text { Overall }\end{array}$ & $\begin{array}{c}(2) \\
\text { Knee height } \\
\text { Urban \& emp. }\end{array}$ & $\begin{array}{c}(3) \\
\text { Child poor health } \\
\text { Overall }\end{array}$ & $\begin{array}{c}(4) \\
\text { Child poor health } \\
\text { Urban \& emp. }\end{array}$ \\
\hline Average sunset time & -0.426 & -0.448 & 0.0341 & -0.020 \\
& $(0.348)$ & $(0.631)$ & $(0.033)$ & $(0.047)$ \\
Observations & 11,254 & 985 & 26,152 & 2,604 \\
R-squared & 0.279 & 0.316 & 0.024 & 0.126 \\
& & & & \\
Mean of Dep. Var. & 47.96 & 48.83 & 0.258 & 0.204 \\
Std.Dev. of Dep. Var. & 3.455 & 3.399 & 0.437 & 0.403 \\
\hline \hline
\end{tabular}

Notes - Data are drawn from the China Health and Retirement Longitudinal Study (CHARLS, 2011-2013). We report estimates of the effect of the average sunset time on knee length and self-reported child poor health. Knee height is available only in wave 1 by the time of writing. All estimates include the same controls as in Model C of Table 4. The overall sample is restricted to individuals living in time zone 7,8 or 9 , between 45 and 70 years old. The other sample is further restricted to employed individuals living in the urban area. The estimated sample is weighted individual survey weights. Significance levels: ${ }^{* * *} p<0.01,{ }^{* *} p<0.05,{ }^{*} p<0.1$. Standard errors are clustered at the city level. 
Table 10: Sunset Time, Sleep and Cognitive Skills among Self-Employed in Urban Areas

\begin{tabular}{|c|c|c|c|c|c|c|c|}
\hline Dependent variable: & $\begin{array}{l}(1) \\
\text { Sleep }\end{array}$ & $\begin{array}{c}(2) \\
\text { Mental }\end{array}$ & $\begin{array}{c}\text { (3) } \\
\text { Numerical }\end{array}$ & $\begin{array}{c}(4) \\
\text { TICS }\end{array}$ & $\begin{array}{c}\text { (5) } \\
\text { Memorial }\end{array}$ & $\begin{array}{c}(6) \\
\text { Draw }\end{array}$ & $\begin{array}{c}(7) \\
\text { CES-D }\end{array}$ \\
\hline Average sunset time & $\begin{array}{c}-0.203 \\
(0.218)\end{array}$ & $\begin{array}{l}0.0145 \\
(0.239)\end{array}$ & $\begin{array}{c}-0.348 \\
(0.269)\end{array}$ & $\begin{array}{c}-0.333 \\
(0.422)\end{array}$ & $\begin{array}{c}0.133 \\
(0.251)\end{array}$ & $\begin{array}{l}0.0134 \\
(0.046)\end{array}$ & $\begin{array}{l}-0.189 \\
(0.701)\end{array}$ \\
\hline $\begin{array}{l}\text { Observations } \\
\text { R-squared }\end{array}$ & 1,239 & 1,226 & 1,226 & 1,226 & 1,226 & 1,138 & 1,127 \\
\hline $\begin{array}{l}\text { Mean of Dep. Var. } \\
\text { Std.Dev. of Dep. Var. }\end{array}$ & $\begin{array}{l}6.330 \\
1.550\end{array}$ & $\begin{array}{l}4.080 \\
1.427\end{array}$ & $\begin{array}{l}3.723 \\
1.675\end{array}$ & $\begin{array}{l}7.803 \\
2.708\end{array}$ & $\begin{array}{l}3.734 \\
1.957\end{array}$ & $\begin{array}{l}0.802 \\
0.398\end{array}$ & $\begin{array}{l}6.314 \\
5.439\end{array}$ \\
\hline
\end{tabular}

Notes - Data are drawn from the China Health and Retirement Longitudinal Study (CHARLS, 2011-2013). All estimates include the same controls as in Model C of Table 4. The sample is restricted to self-employed individuals living in the urban area of time zone 7, 8 or 9 , between 45 and 70 years old. The estimated sample is weighted using individual survey weights. Significance levels: ${ }^{* * *} p<$ $0.01,{ }^{* *} p<0.05,{ }^{*} p<0.1$. Standard errors are clustered at the city level. 
Table 11: Sunset Time, Sleep and Cognitive Skills among Farmers

\begin{tabular}{lccccccc}
\hline \hline & $(1)$ & $(2)$ & $(3)$ & $(4)$ & $(5)$ & $(6)$ & $(7)$ \\
Dependent variable: & Sleep & Mental & $\begin{array}{c}(4) \\
\text { Numerical }\end{array}$ & $\begin{array}{c}\text { TICS } \\
\text { Memorial }\end{array}$ & $\begin{array}{c}\text { Draw } \\
\text { CES-D }\end{array}$ \\
\hline Average Sunset Time & -0.145 & -0.0826 & -0.187 & -0.27 & 0.0504 & -0.0527 & 0.813 \\
& $(0.147)$ & $(0.136)$ & $(0.125)$ & $(0.218)$ & $(0.174)$ & $(0.0319)$ & $(0.497)$ \\
& & & & & & & \\
Observations & 9,999 & 9,889 & 9,889 & 9,889 & 9,889 & 9,551 & 9,139 \\
R-squared & 0.028 & 0.185 & 0.257 & 0.29 & 0.115 & 0.224 & 0.104 \\
Mean of Dep. Var. & 6.264 & 3.308 & 2.901 & 6.209 & 3.16 & 0.589 & 8.982 \\
Std. Dev. of Dep. Var. & 1.843 & 1.566 & 1.93 & 3.013 & 1.825 & 0.492 & 6.247 \\
\hline \hline
\end{tabular}

Notes - Data are drawn from the China Health and Retirement Longitudinal Study (CHARLS, 2011-2013). All estimates include the same controls as in Model C of Table 4. The sample is restricted to farmers in rural areas of time zone 7, 8 or 9 , between 45 and 70 years old. The estimated sample is weighted using individual survey weights. Significance levels: ${ }^{* * *} p<0.01,{ }^{* *} p<0.05,{ }^{*} p<0.1$. Standard errors are clustered at the city level. 
Figure 1: Sunset Time in China on June 21st

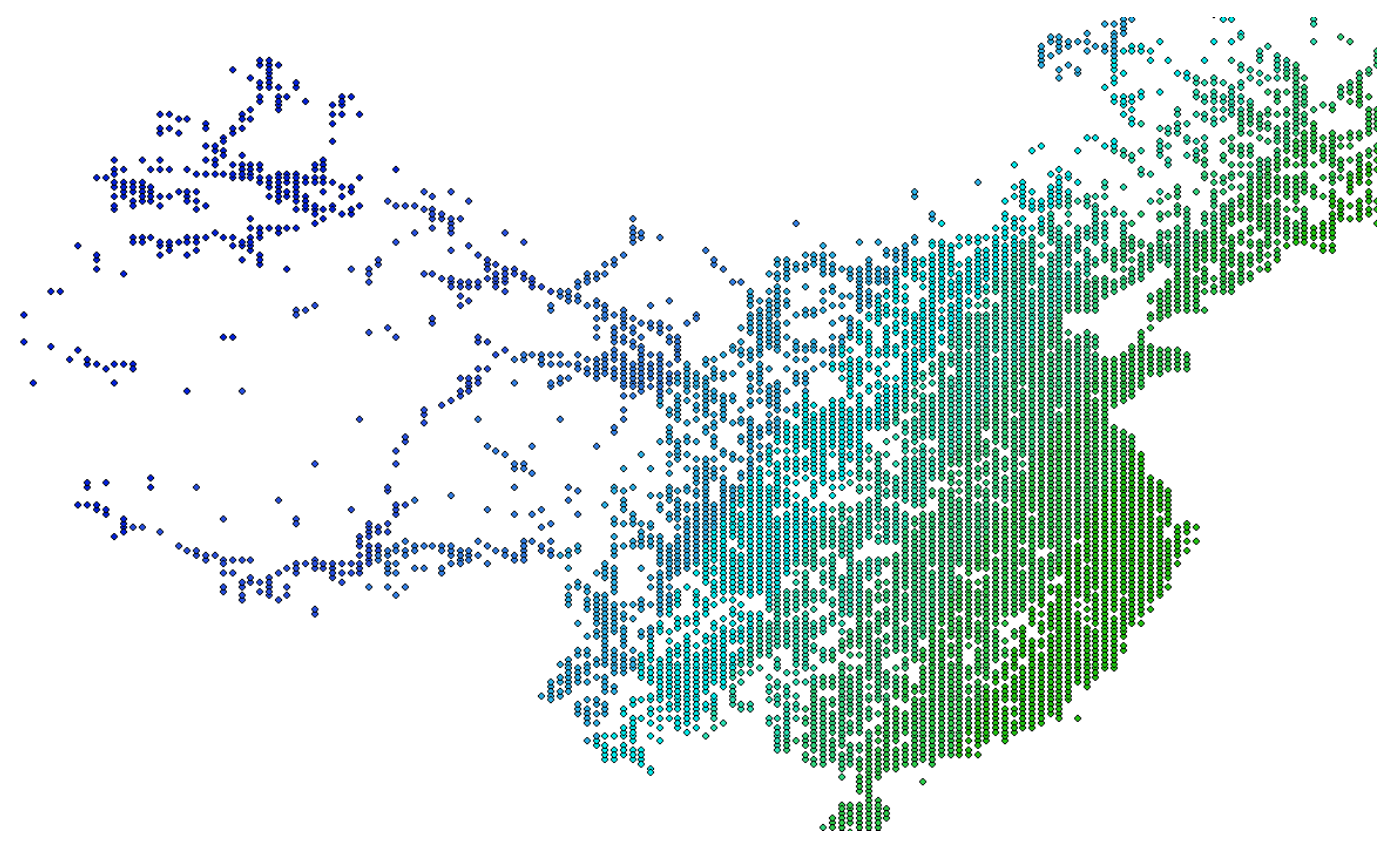

Notes - Sunset time for Chinese cities was computed using the NOAA Solar Calculator. Sunset time goes from light green(early sunset) to dark blue (late sunset). The earliest sunset time in the data occurs at $18.53 \mathrm{pm}$, the latest sunset in the data occurs at $22.29 \mathrm{pm}$. 
Figure 2: China time zones according to the Coordinated Universal Time (UTC)

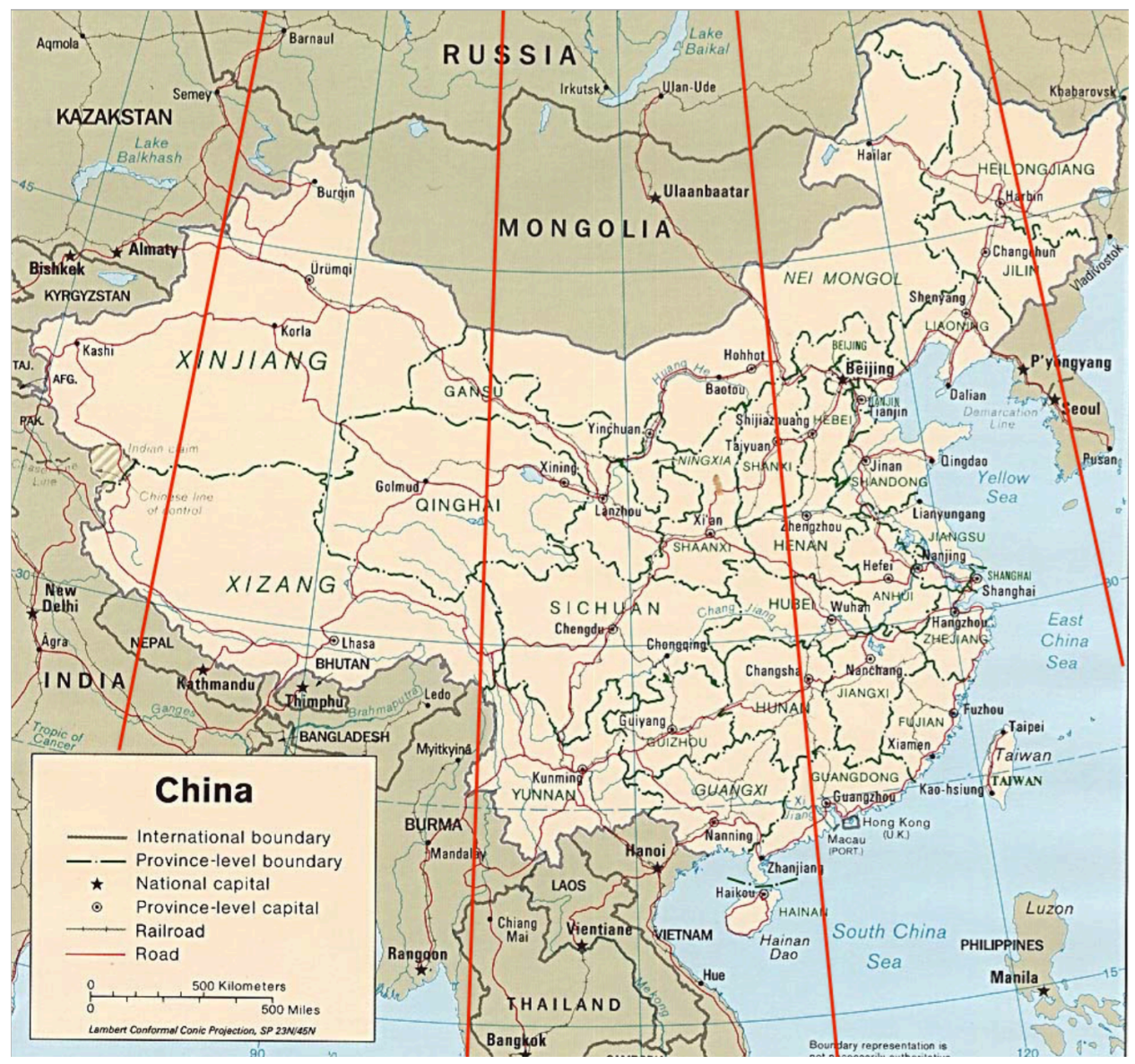

Notes - This map was downloaded from http://www.lib.utexas.edu/maps/middle_east_and_asia/china_pol96.jpg. The red vertical lines (elaborated by the authors) correspond to the UTC time zone areas. 
Figure 3: The four economic regions of China

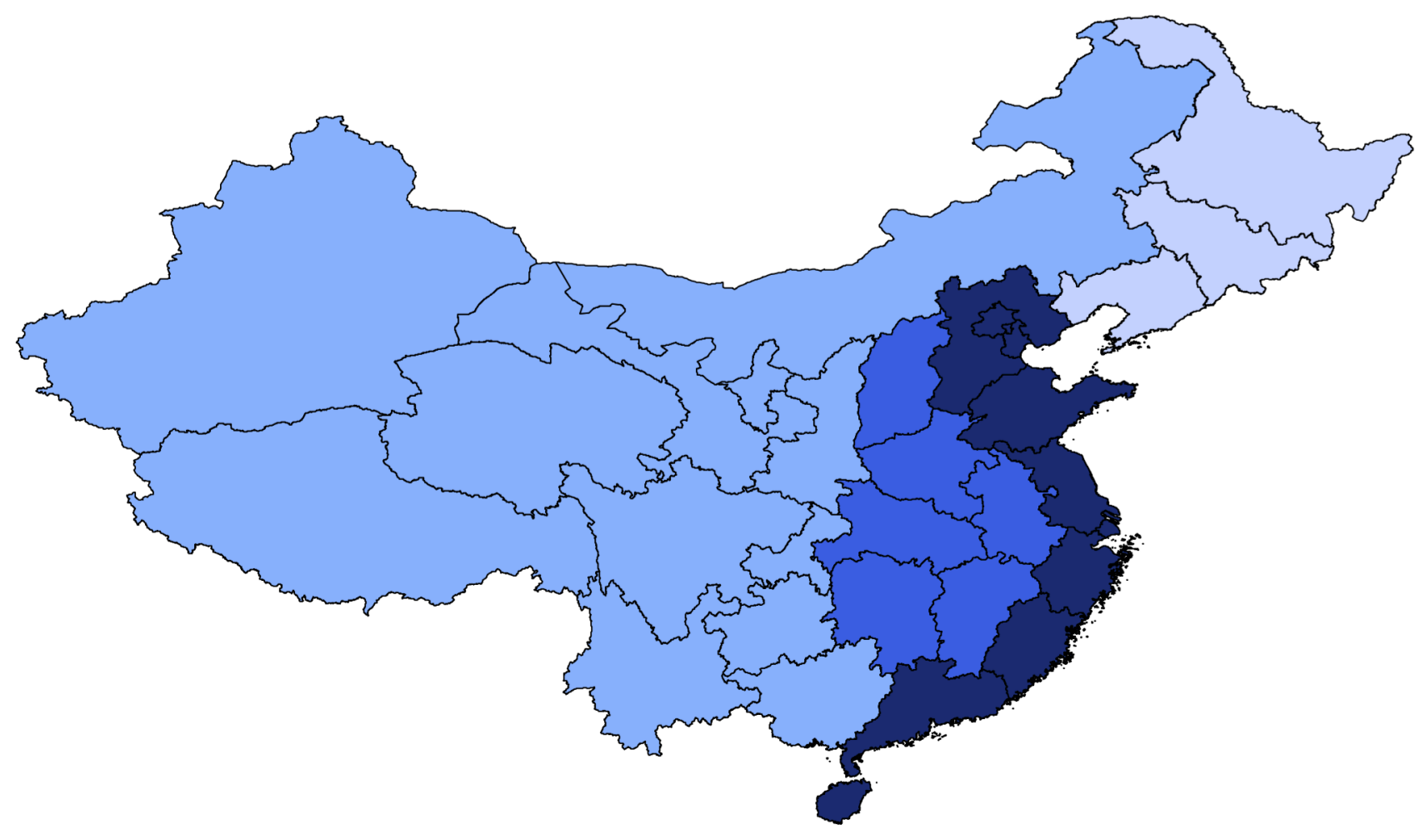

\section{Region}

\begin{tabular}{l}
\hline Eastern \\
\hline$\quad$ Central \\
\hline$\quad$ Western \\
$\square$ Northeastern
\end{tabular}




\section{Appendix A - For Online Pubblication}

Table A.1: Variation in average sunset time by region

\begin{tabular}{lccc}
\hline \hline Region & Min & Max & $\mathrm{N}$ \\
\hline & & & \\
1 & 18.02 & 19.48 & 536 \\
2 & 17.96 & 18.68 & 1,163 \\
3 & 18.23 & 18.78 & 652 \\
4 & 17.29 & 18.00 & 285 \\
\hline \hline
\end{tabular}

Notes - For each region we report the minimum and the maximum value of the average sunset time in our main sample (employed and urban aged 45 to 70$)$.

Table A.2: First-stage and 2SLS: Sleeping Time and Cognitive Skills (Urban and Employed with non-Missing Sleeping Hours)

\begin{tabular}{|c|c|c|c|c|c|c|c|}
\hline Dependent variable: & $\begin{array}{c}(1) \\
\text { Sleep }\end{array}$ & $\begin{array}{c}(2) \\
\text { Mental }\end{array}$ & $\begin{array}{c}(3) \\
\text { Numerical }\end{array}$ & $\begin{array}{c}(4) \\
\text { TICS }\end{array}$ & $\begin{array}{c}(5) \\
\text { Memorial }\end{array}$ & $\begin{array}{c}(6) \\
\text { Draw }\end{array}$ & $\begin{array}{c}(7) \\
\text { CES-D }\end{array}$ \\
\hline Average sunset time & $\begin{array}{c}-0.630^{* * *} \\
(0.197)\end{array}$ & & & & & & \\
\hline Sleep hours & & $\begin{array}{c}0.304 \\
(0.190)\end{array}$ & $\begin{array}{c}0.765^{* * *} \\
(0.278)\end{array}$ & $\begin{array}{c}1.069^{* * *} \\
(0.401)\end{array}$ & $\begin{array}{l}-0.267 \\
(0.411)\end{array}$ & $\begin{array}{c}0.0653 \\
(0.0548)\end{array}$ & $\begin{array}{l}-2.072^{*} \\
(1.207)\end{array}$ \\
\hline Observations & 2,296 & 2,260 & 2,260 & 2,260 & 2,260 & 2,238 & 2,191 \\
\hline Mean of Dep. Var. & 6.526 & 4.524 & 4.009 & 8.533 & 4.234 & 0.844 & 5.611 \\
\hline Std.Dev. of Dep. Var. & 1.517 & 0.934 & 1.437 & 1.918 & 1.898 & 0.363 & 4.785 \\
\hline
\end{tabular}

Notes - Data are drawn from the China Health and Retirement Longitudinal Study (CHARLS, 2011-2013). Col (1) reports the first-stage and all the rest columns report IV estimates using only individuals whose sleeping hours are not missing in the dataset. All estimates include the same controls as in Model $\mathrm{C}$ of Table 4. The sample is restricted to employed individuals living in the urban area of time zone 7,8 or 9 , between 45 and 70 years old. The estimated sample is weighted using individual survey weights. Significance levels: ${ }^{* *} p<0.01,{ }^{* *} p<0.05,{ }^{*} p<0.1$. Standard errors are clustered at the city level. 
Table A.3: Unconfoundness Test, Model A: Sunset Time effect on Knee Height and Self-Reported Child Poor Health

\begin{tabular}{lcccc}
\hline \hline $\begin{array}{l}\text { Dependent variable: } \\
\text { Sample: }\end{array}$ & $\begin{array}{c}(1) \\
\text { Knee height } \\
\text { Overall }\end{array}$ & $\begin{array}{c}(2) \\
\text { Knee height } \\
\text { Urban \& emp. }\end{array}$ & $\begin{array}{c}\text { Child poor health } \\
\text { Overall }\end{array}$ & $\begin{array}{c}(4) \\
\text { Child poor health } \\
\text { Urban \& emp. }\end{array}$ \\
\hline Average sunset time & $\begin{array}{c}-0.712^{* * *} \\
(0.221)\end{array}$ & -0.576 & $0.0729^{* * *}$ & $0.0803^{* *}$ \\
& & $(0.402)$ & $(0.0243)$ & $(0.0378)$ \\
Observations & 11,254 & 985 & 26,152 & 2,604 \\
R-squared & 0.279 & 0.316 & 0.024 & 0.126 \\
& & & & \\
Mean of Dep. Var. & 47.96 & 48.83 & 0.258 & 0.204 \\
Std.Dev. of Dep. Var. & 3.455 & 3.399 & 0.437 & 0.403 \\
\hline \hline
\end{tabular}

Notes - Data are drawn from the China Health and Retirement Longitudinal Study (CHARLS, 2011-2013). We report estimates of the effect of the average sunset time on knee length and self-reported child poor health. Knee height is available only in wave 1 by the time of writing. All estimates include the same controls as in Model A of Table 4. The overall sample is restricted to individuals living in time zone 7, 8 or 9, between 45 and 70 years old. The other sample is further restricted to employed individuals living in the urban area. The estimated sample is weighted using individual survey weights. Significance levels: ${ }^{* * *} p<0.01,{ }^{* *} p<0.05,{ }^{*} p<$ 0.1. Standard errors are clustered at the city level. 